Portland State University

PDXScholar

1-27-1995

\title{
Sex-role Stereotypes: How Far Have We Come?
}

Erica D. Monte

Portland State University

Follow this and additional works at: https://pdxscholar.library.pdx.edu/open_access_etds

Part of the Sociology Commons

Let us know how access to this document benefits you.

\section{Recommended Citation}

Monte, Erica D., "Sex-role Stereotypes: How Far Have We Come?" (1995). Dissertations and Theses. Paper 4945.

https://doi.org/10.15760/etd.6821

This Thesis is brought to you for free and open access. It has been accepted for inclusion in Dissertations and Theses by an authorized administrator of PDXScholar. Please contact us if we can make this document more accessible: pdxscholar@pdx.edu. 


\section{THESIS APPROVAL}

The abstract and thesis of Erica D. Monte for the Master of Science in Sociology were presented January 27, 1995, and accepted by the thesis committee and the department. COMMITTEE APPROVALS :

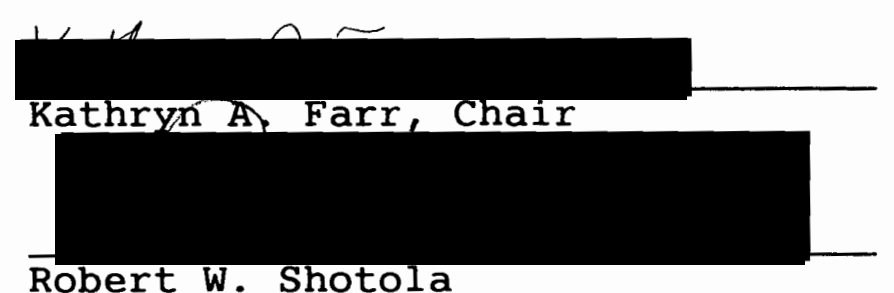
Robert W. Shotola

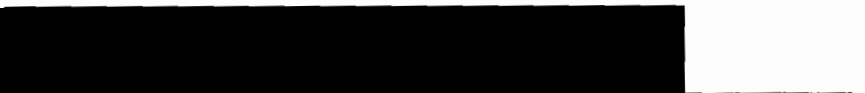

Michael A. Toth

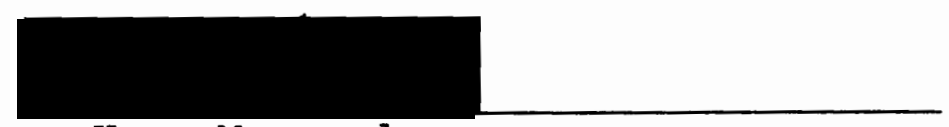

Hugo Maynard

Representative of the office of Graduate Studies

DEPARTMENT APPROVAL:

Robert W. Shotola, Chair

Department of Sociology

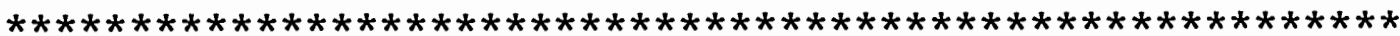

ACCEPTED FOR PORTLAND STATE UNIVERSITY BY THE LIBRARY by on

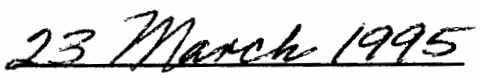




\section{ABSTRACT}

An abstract of the thesis of Erica D. Monte for the Master of Science in Sociology presented January 27, 1995.

Title: Sex-Role Stereotypes: How Far Have We Come?

Parents are the first source of a child's learning of her or his gender. In fact, sex-role stereotyping of infants by parents may occur within the first 24 hours of birth.

This study examined the nature of parental stereotyping on the basis of their infant's sex by obtaining parents' descriptions of their newborn and toy and clothing preferences for their newborn.

In 1974 , Rubin found that parents responded stereotypically to their infants on the basis of sex. Following Rubin's interview approach, 50 parent pairs from two urban hospitals were asked to participate in a parent-infant study and were subsequently interviewed 24 hours postpartum. Parents were asked open-ended descriptive questions about their newborn, given a semantic differential scale of 18 bi-polar objectives, 
asked about the importance of others recognizing their baby's sex, and asked a set of questions relating to the preference of clothing and toy choices for their newborn.

Findings suggest that parents do stereotype their infants on the basis of biological sex. Sons were more likely to be described as strong, perfect, big or bigfeatured and energetic, 'while daughters received more descriptions that mentioned their eyes, skin, or facial features and were also more likely to be described as small, tiny, or weak. Parents of boys were also more likely to state a preference for gender-specific toys and clothing. Infant sex did not make a notable difference on the importance that parents attributed to others recognizing their baby's sex. Fathers were more likely to perceive and describe their daughters more stereotypically than were mothers of either daughters or sons.

Further studies to investigate gender stereotyping and its consequences as well as the interplay between the macro and micro levels of gender relations in society are suggested. 
'SEX-ROLE STEREOTYPES: HOW FAR HAVE WE COME?'

by

ERICA D. MONTE

A thesis submitted in partial fulfillment of the requirements for the degree of

\author{
MASTER OF SCIENCE \\ in \\ SOCIOLOGY
}

Portland State University

1995 
TABLE OF CONTENTS

PAGE

LIST OF TABLES

LIST OF FIGURES

CHAPTER

I. INTRODUCTION

II . LITERATURE REVIEW AND

THEORETICAL FRAMEWORK . . . . . . . . . . . 4

Empirical Literature Review . . . . . 4

Traditional Theories . . . . . . . 15

Gender Socialization Within a

Feminist Framework . . . . . . . 24

III . METHODOLOGY • . . . . . . . . . . . . . . 34

Sample and Settings . . . . . . . . 35

Measures . . . . . . . . . . . 40

Data Analysis . . . . . . . . . . 45

IV. RESULTS • . • . . . . . . . . . . . . . . . 47

Description of the Sample . . . . . . 47

Frequencies . . . . . . . . . . 51

Summary - . . . . . . . . . . . 65

V. DISCUSSION AND CONCLUSIONS • • • • • • • . 67

Comparison of Prior and

Current Findings . . . . . . . 67

Conceptual Discussion . . . . . . 73 


$$
\text { iv }
$$

PAGE

Limitations of the Study . . . . . . 74

Concluding Comments . . . . . . . . 75 REFERENCES •. • . . . . . . . . . . . . . . 78

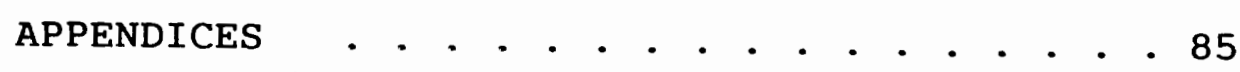

A. CONSENT FORM . . . . . . . . . . . 86 .

B. INSTRUCTION FOR SEMANTIC DIFFERENTIAL . . . . . . . . . . 88

C. OBJECTIVE DATA SHEET . . . . . . 90

D. BIRTH CERTIFICATE WORKSHEET • • . 92

E. RUBIN'S SEMANTIC DIFFERENTIAL FINDINGS . . . . . . . . . . . 94 


\section{LIST OF TABLES}

TABLE

PAGE

1 Sex of Infant by Hospital . . . . . . . . 48

2 Parents' Education, by Percent . . . . . . . 48

3 Parents' Age, by Percent . . . . . . . . . 49

4 Parents' Race, by Percent . . . . . . . 50

5 Newborns' Race, by Percent . . . . . . . 51

6 Parents' Open-Ended Descriptions, by

Infant Sex, Frequencies,

and Percentages . . . . . . . . . . 53

7 Mean Ratings on Semantic Differential

Scale, by Sex of Parent and Sex

of Infant . . . . . . . . . . . . . 60

8 Percentage of Parents Mentioning

Preferences for Toys and Clothing,

Sex of Infant . . . . . . . . . . . 63

9 Percentage of Parents Attributing

Different Levels of Importance to

"Others Recognizing Baby's Sex

Right Away", by Sex of Infant . . . . . . 64 


\section{LIST OF FIGURES}

\section{FIGURES}

PAGE

1 Most Common Open-Ended Descriptors Used by Parents Toward Newborn . . . . . . . 42

2 Semantic Differential Scale . . . . . . . . 43

3 Questions Asked of Parents in Regard to Toy and Clothing Preference . . . . . . . . . 44 
CHAPTER I

\section{INTRODUCTION}

A boy and his father were involved in a serious automobile accident. The father was killed instantly; the son was severely injured. An ambulance rushed him to the nearest hospital, and a prominent surgeon was summoned to perform an immediate operation. Upon entering the operating room, however, the surgeon exclaimed, "I can't operate on this boy. He's my son." The question is: How can this be? (Basow, 1986 p.3).

The answer to the above story is that the surgeon is the boy's mother! Susan Basow points out that most people will create answers to the above story which reflect a stereotypic perception of appropriate sex-role occupations, e.g. suggesting that the surgeon is the boy's stepfather. The fact that most people do not answer the riddle correctly reflects the existence of gender stereotypes. As Basow points out, sex-role stereotypes restrict an individual's life and shape society's image of appropriate roles for women and men. Stereotypes are not facts; rather, they are prejudgments or overgeneralizations about people in a social category, the category in this research being gender. Parents are the first source of a child's 
understanding of her or his gender (Lips, 1991; Katz, 1979): Traditionally, children were thought to acquire their gender identity when they were preschoolers (between the ages of three to five) and had the cognitive ability to differentiate between maleness and femaleness (Kohlberg, 1966; Kohlberg and Ullian, 1974). However, in a widely-cited study, Rubin (1974) found that within 24 hours of birth, new parents responded stereotypically to their infants, perceiving daughters as littler, finer-featured, and more inattentive than sons, even though the babies here did not differ significantly in terms of birth length, weight, or Apgar scores (two scores assigned five and ten minutes postpartum to represent physician ratings of infants' color, muscle tonicity, reflex, heart, and respiratory rates)

The purpose of this research was to examine sexrole stereotypes and the belief that they are based only on actual biological sex differences. Specifically, this research explored sex-role stereotyping of infants by their parents. The expectation is that parents do apply sex-role stereotypes to infants and that these overgeneralizations function in American culture as socializing elements.

This paper presents a replication of Rubin's 
original research on sex-role stereotypes. Every precaution has been taken to ensure that this research replicated Rubin's original. This was done by using Rubin's original semantic differential scale and instructions with each interview. The method used in this research was also borrowed from Rubin's original study. For example, subjects were approached in the same manner in this study as they were in Rubin's. Data analysis in this study also mirrored Rubin's original by the choice of statistics and descriptive information. The purpose of replicating Rubin's 1974 study was to examine whether the gender stereotyping of infants by parents identified by Rubin still persists two decades later despite the increased attention to and literature on gender research. 
CHAPTER II

LITERATURE REVIEW AND THEORETICAL FRAMEWORK

\section{Empirical Literature Review}

Because of the early and lengthy interaction and close bonds between parents and children, parents are the primary socializing agent in American society (Basow, 1992). As shown by Rubin (1974), based on their sex, parents stereotypically describe their infants within 24 hours of birth. Of course there are other agents in society, separate from the home, which also contribute to a child's socialization. However, in this research, my focus was on parents' role in the initial gender socialization of their infants.

Parents socialize their children toward specific gender roles based on their sex in a variety of ways. The following empirical research relating to parents has been separated into three categories: early sex-role socialization, toys and decor, and activities. Some research on later sex-role socialization is also described to illustrate how gender roles are reinforced beyond early parental socialization. The research on gender-role socialization is very extensive and to cover 
it comprehensively is beyond the scope of this thesis. Rather, I have chosen to describe literature on sex-role socialization that best emphasizes the process of learning gender.

Early sex-role socialization. Using Rubin's interviewing approach, Sweeney and Bradbard (1987) found that immediately following birth, parents sex type their infants. In this study, parents perceived girls to be smaller, finer, less coordinated, more delicate, quieter, and weaker than boy babies. These descriptions were solely a function of the baby's sex.

In another study, McGuire (1988) found that those parents who noted more evidence of masculinity or femininity in their own child were more likely to believe there were many differences overall between boys and girls. The descriptors these parents used fit with sex-stereotypic norms, e.g., gentle for girls, strong and active for boys. Another study (Paludi and Guleo, 1986) found that adults perceived infants' behavior as feminine if they were told the baby was a girl and masculine if they were told the baby was a boy. If boy infants are thought of as stronger, they may be treated as more self-sufficient than girl infants. There is some evidence that this does occur. For example, the findings in several studies (Condry and Condry, 1983; 
Culp, Cook, and Houseley, 1983) indicated that women responded more quickly to crying girls than boys. Baby girls are also stereotyped as more "dependent" than baby boys, which contributes to this treatment.

Even prior to birth, parents have been found to link fetal activity to sex of the fetus: if fetal activity is very strong, the fetus is assumed to be male (Doyle, 1983; Sweeney and Bradbard, 1987). Hoffman (1977) and Williamson (1976) also argue that sex-typing of infants begins prior to birth in the form of a higher preference placed on male children. When parents were asked about their preference for a male infant, they responded with reasons related to the strength and vitality of males. This value preference for males by parents also included the importance of males' carrying on the family name.

The use of stereotypes by parents seems to help them categorize babies in familiar ways. Parents studied by Seavey and Colleagues (1975) made distinguishable responses to male and female babies only after they inquired about and were told the gender of the infant. Then, parents defined girls as fragile and soft, while boys were recognized for strength of grasp. When adults were asked to play with and describe babies 
whose gender they did not know, they became uncomfortable.

It is sometimes argued that parents do not realize the extent to which they are treating boys and girls differently. In the research of Will, Self and Datan (1976), mothers reported that they did not differentiate babies according to gender because boys and girls were alike at this age and should not be treated differently! However, observations of them interacting with a six month old infant (half of the mothers played with an infant dressed in blue, "Adam", and later half of the mothers played with the same infant wearing a pink dress, "Beth") proved differently. These mothers were observed to ascertain which of the three toys--a doll, toy train, or a fish--they would provide the child. The mothers were more likely to offer the doll to "Beth" and the toy train to "Adam". They also smiled at and held the baby more closely when they believed the baby was "Beth".

Toys and Decor. Sex stereotyping is also apparent in parents' choice of toys and decor for their babies. The decorations and toys provided in the rooms of newborns vary depending on the baby's sex (Rheingold and Cook, 1975). Boys' rooms are more likely to contain such things as educational tools, military equipment, 
spatial-temporal objects, sports equipment, and vehicles, while girls' rooms are provided with dolls, houses, and floral or lace decor. Boys' toys were also found to encourage activities outside the home, while the toys provided the girls varied less in type and encouraged play within the home. These socializing objects that are provided for the children are internalized as reflections of appropriate behavior and identity. Rheingold and cook also found that boys' toys prompt more flexible responses, diverse reactions, and improvisational play. The toys that boys and girls learn to prefer shape the acquisition of identities, which ultimately shape adult roles.

Interestingly, in another study, Kutner and Levinson (1978) found that toy salespeople selected toys for infants according to their sex, and apparently this behavior fits with the desires of parents. O'Brien and Huston (1984) found that both mothers and fathers gave the highest ratings to masculine-typed toys for their sons and feminine-typed toys for their daughters. It is also interesting to note that parents typically are more concerned about opposite-sex toy choices for boys than for girls (Fling and Manosevitz, 1972; Lansky, 1963). Girls tend to have more freedom in crossing over gendertyped play, whereas male roles are more rigidly defined. 
Social sanctions may be brought against boys who are considered sissies, but not against girls who are thought to be tomboys (Andersen; 1993). For girls, being a tomboy is simply more acceptable than being a sissy is for boys.

Basow (1992) explains that parents "strongly discourage" sons from participating in cross-sex activities. Most specifically, fathers have negative responses to their sons playing with female-related toys. Another example of toys shaping children's gender-typed future is Hoffman's work (1979). This analysis of sex-specific toys showed that girls' toys did not make cognitive demands on them or prepare girls for a career-oriented future; rather, they tended to emphasize domestic roles and motherhood. In contrast, boys' toys were more expensive, more varied, and creative (for example, science kits and construction sets). Having different experiences in their infancy and youth, boys and girls get different occupational messages. For example, both boys and girls may receive the message that careers are only important for boys, and child care is only a female responsibility. Basow (1992) argues that a consequence of playing with different toys may be the development of different abilities. For example, girls will develop better 
verbal abilities because playing house involves a large amount of talk, while boys will excel at visual-spatial and manual abilities because toys such as tool sets refine these skills.

Activities. In addition to sex-stereotypic labels, toys, and clothing, parents also encourage sexappropriate activities. White and Brinkerhoff (1981) found distinct differences in types of chores girls and boys were expected to perform. In a state-wide sample (Nebraska), girls were expected and encouraged to do "women's work": cleaning house, doing dishes, cooking; boys did "men's work": taking out the garbage and yard work.

Observations of children during play also revealed the importance of learning sex-stereotypic gender roles (Lever, 1978). Found through observations, questionnaires, interviews, and children's activity diaries was that girls tended to define their activities as "play" and not involving specific goals. Boys, on the other hand, defined their activities as "games" with structured teams and a recognized goal. Girls were also found to be more cooperative, more involved in repetitive passive play, and less difectly competitive. Boys allowed more role differentiation, face-to-face competition, and elaborate rules, and they more rigidly 
adhered to the stated rules. These differences in activities between boys and girls are likely a consequence of early sex-role socialization and especially of that which reinforces gender-specific identities and abilities.

Childrearing emphases are found to differ by the child's gender. Parents of boys place a greater emphasis on achievement, competition, control of feelings, and conformity to rules from early on, while parents of girls place more focus on close interpersonal relationships, encouragement to talk about troubles, reassurance, and frequent expression of physical attention (Block, 1973). MacCoby and Jacklin (1987) also found that boys received more pressure for achievement and independent exploration in their activities.

Later sex-role socialization. Even though gender roles are established early, sex-role socialization continues throughout one's life. Fagot (1978) argues that positive responses to children are contingent on the sex-role appropriateness of the child's behavior. In their review of the literature, MacCoby and Jacklin (1974) found documentation of continuing parental encouragement of sex-typed behavior. 
Once children begin school, they are exposed to other socializing agents. Most specifically, teachers play a significant role in gender socialization (Basow, 1992). Epperson found that boys tend to dominate the classroom environment (1988). The same study also found that boys were more likely to receive teacher attention, demand help, call out in class, and be complimented by the teacher. When girls received more attention than boys, it was in the form of reinforcement for being quiet and compliant, and Sadker and Sadker (1986) found that when girls gave a correct answer in school, they were more likely to receive acceptance ("OK") rather than praise ("Excellent") as boys did. Additionally, when a girl called out an answer in class without raising her hand, she was likely to be scolded, while boys calling out answers were more likely to receive acceptance from teachers.

College teachers also tend to treat the sexes differently (Hall and Sandler, 1982). Female students have been found to be called on less often and when speaking, to be interrupted and ignored more often than male students. Males were often found to receive more encouragement while pursuing their education. Textbooks also portray men and women in gender-stereotypic roles (Andersen, 1993). Men are represented in more paid 
occupations than women, and boys are shown as being physically active, whereas girls are shown to be more involved in verbal behavior, more conforming, and more preoccupied with fantasies (Richardson, 1981).

Peers further serve to reinforce gender stereotypes. Individuals who conform to traditional sex roles from preschool through high school are more socially acceptable to their peers (Martin, 1989). Moreover, peers seem to be more influential in validating sex-role conformity for males than for females (another example of males' more intensified gender-role socialization). Fagot's research showed that preschool boys who preferred feminine sex-typed toys played alone more often and received negative feedback from other boys in the class. It was also found that through teenage years, boys spent more time with peers, while girls spent more time with adults. This gender segregation tends to separate the sexes and their behavior even more.

Finally, the media also plays an influential role in gender socialization and formation of gender-role stereotypes. It is estimated that children spend onethird of their lives in front of a TV set (Basow, 1992). This means that by age 16 , the average child has spent more time watching television than in a classroom. 
Gender stereotypes are most distinct on commercials. When women are shown as employed, it, is often in traditionally feminine roles. Males, on the other hand, dominate the authoritative roles and voice-overs in commercials by $90 \%$ (Basow, 1992). Although commercials arguably constitute the most sexist programming on television, music television aimed at preadolescents and teenagers strongly reinforces stereotypic images of the sexes. Most common on music television are male teenage fantasies (Brown and Campbel1, 1986). Females are most commonly shown trying to gain the attention of a man, are highly likely to be portrayed as sex objects, and unlikely to be shown in professional work. Basically, strong sex-role stereotypes are communicated by television: males are portrayed as more important and dominant than women, while women are seen as subordinate and sexualized.

Summary. Sex-role socialization begins at birth. Socializing infants toward a specific gender is apparent in all aspects of children's lives: toys, activities, play, and treatment by others. This gender socialization is more rigid for boys, and ultimately greater value is placed on the male role, while the female role becomes devalued. Sex-role socialization 
begins with parents and is strengthened by teachers, peers, and the media.

\section{Traditional Theories}

Traditional sex-role theories have focused primarily on the learning process in sex-role socialization. There are four particularly well-known theories (and theorists) which address sex-role socialization and gender development: psychoanalytic (Freud, 1925), social learning (Bandura, 1963), cognitive development (Kohlberg, 1969), and gender schema (Bem, 1981). Each theory concentrates on different phases and components of development, and thus offers different interpretations of the sex-role socialization process. Following is a brief description of the four perspectives, and then a consideration of feminist viewpoints on sex-role socialization.

Psychoanalytic. Psychoanalytic theory is perhaps the best known theory of sex typing. Sigmund Freud, one of the most influential psychologists of the 20 th century, was the first major scholar to develop a theory explaining how and why people internalize genderspecific personalities (Sapiro, 1994). Psychoanalytic theory emphasizes the significance of biological and 
anatomical factors combined with parental identification.

Psychoanalytic theory argues that it is between the ages of three and six that the development of boys and girls diverge. It is during this age that boys develop an attachment for the mother and begin to see the father as a competitor. Freud believed that boys are unable to acknowledge their negative feelings for their fathers and unconsciously begin to believe that the father also sees them as a competitor. Subsequently, the boy fears castration by his father. Freud argued that this fear of castration is a consequence of boys realizing that not everybody has a penis, and some people (women) have already been castrated. Psychoanalytic theorists believe this fear is so intense that the boy resolves his fear by converting his attraction to his mother to filial affection, rejecting his mother's feminine attributes and identifying with his father, thus incorporating his father's personality into his own (Lips, 1993).

The girl's identification with feminine behavior begins when she notices that boys have something she does not: a penis. Psychoanalytic theorists label the consequence of this realization "penis envy". Progressively up to age six, she realizes that she will 
never have a penis, is attracted to her father as a substitute for the missing organ, and comes to fear her mother as a rival. Her anxiety is relieved by an unconscious identification with her mother and internalization of feminine characteristics and by a filial affection for her father. The theory suggests that since a girl realizes she cannot ever be a male, she becomes more feminine so that she can be valued by a male and gain the missing penis (Nielsen, 1990).

For both sexes, identification with the same-sex parent is the primary source of learning gender (Bem, 1984). Because the fear of castration is believed to be stronger than penis envy, a male's gender identity is viewed as stronger than that of the female (Basow, 1986). Psychoanalytic theorists believe that same-sex identification is necessary for a mentally healthy individual and for the development of masculine and feminine personalities. Freud viewed this process as biologically based since the awareness of anatomical sex differences is the force driving same-sex parental identification and the eventual internalization of appropriate gender-typed behavior.

There is little reliable, empirical support for Freud and the psychoanalytic perspective on the development of gendered adults. There are also many 
criticisms regarding his research methods (Sapiro, 1994). For example, Freud used his patients and colleagues' patients for his subjects, and his sample was small. The traditional psychoanalytic perspective also neglects the role of society and culture in shaping individuals. Moreover, other work does not support Freud's assertion that mental health requires appropriately gendered personalities. For example, when considering the sex type of both parents, Spence and Helmreich (1978) found that the most healthy homes for children are the ones in which both parents are androgynous (i.e. have both feminine and masculine attributes. For example, they are helpful to others and active).

Social Learning. Social learning theories of gender development differ from psychoanalytic theories by viewing gender identity as a conscious and overt product of learning rather than as a result of innate and biologically determined developments (Basow, 1986).

Social learning theory suggests that a child develops gender identity and a sex role through a learning process which includes modeling, imitation, and reinforcement (Bandura, 1977). This perspective is based on an assumption that girls will be taught to be feminine, and boys will be taught to be masculine. 
Children are believed to develop an awareness of the two sex roles within the first year of life directly through differential treatment, rewards, and punishments and indirectly from observing and modeling (DelBoca and Ashmore, 1980).

When a child is regularly reminded of her/his sex and is supported for performing sex-appropriate behaviors and activities, it progressively becomes rewarding to think of the self as a boy or a girl (Lips, 1993). The formation of a specific sex role tends to guide the establishment of a gender identity that is accepted by society.

Support for learning theories comes from research which indicates that awareness of gender and sex-role stereotypes tend to increase with age and a wider exposure to gender-differentiated arrangements. Vender and Snyder (1966) found that by age five, children had an 84 \% accuracy rate in matching specific objects with sex roles (for example, lipstick or a pipe). Bandura (1984) also found that both sexes, as early as three years old, imitate same-sex models more than other-sex models.

Although there tends to be much support for social learning theories, they may be insufficient for the complete explanation of gender development. MacCoby and 
Jacklin's review.(1974) found that not all children choose same-sex models. Perry and Bussey (1979) also point out that a child may model a same-sex parent only if the parent is viewed as representative of that sex. Cognitive Development. Cognitive development theory (Kohlberg, 1969) takes a different perspective than social learning theory by focusing on the child as an active participant in her or his sex-role socialization. It is based on the child's cognitive ability to intellectually differentiate between boy and girl.

Cognitive development theory proposes that between the ages of three and five, a child has the cognitive ability to acquire "gender constancy", at which point she or he will be able to understand that females and males are different. Children subsequently begin to categorize specific behaviors as male or female (Lips, 1993). According to the cognitive development perspective, once a child has classified herself or himself as female or male, she/he will use this classification to organize her/his own behaviors.

This perspective derives support from studies which show that children increase their accuracy at gender differentiation and labeling from ages two to five years old (Coker, 1984). More support for Kohlberg's 
cognitive developmental theory comes from research by McArthur and Eisen (1976) who found that starting in nursery school, over $90 \%$ of the children begin to favor same-sex characters in a story. When asked about this preference, the children responded with answers relating to identification with the sex of the character. This also supports the social learning perspective on gender. The cognitive development and social learning theories are compatible with one another, although theorists in each perspective have tended to criticize one another. One problem with cognitive development theory is that not all findings regarding it are consistent. More specific is the issue that cognitive development theory suggests that sex-typing by parents is a result of the child's individual gender formation, when in fact much sex-typing by parents has occurred prior to the suggested age at which there is the cognitive ability to learn the appropriate gender (Bussey and Bandura, 1984). A methodological bias is that Kohlberg used interviews with males only to support his theory (Weitz, 1977). Clearly to study gender differences, the sample needs to include both genders.

Gender Schema Theory. Sandra Bem (1981) developed a gender theory that integrates both cognitive developmental and social learning theories. Bem's 
gender schema theory proposes that there is a gender schematic processing phase which occurs developmentally. This involves a generalized readiness by the child to encode and organize information according to society's definitions of maleness and femaleness which ultimately leads to sex-typing (Bem, 1984). As children learn their particular society's gender schema, they learn which characteristics are associated with each sex.

Bem (1984) suggests that people will differ to the extent that they use a gender schema to process information. Those individuals who are more sex-typed are believed to be those who have a stronger tendency to use gender schematic processing (Sapiro, 1994). Bem's theory states that individuals rely on the use of gender schematic processing in different degrees depending upon how strong the gender dichotomy was stressed during primary socialization.

Empirical support for Bem's gender schematic theory was found in research showing that sex-typed individuals showed more grouping of gender-relevant items in a free recall memory test than did non-sex-typed individuals, suggesting that sex-typed individuals organize and process information using gender schema (Basow, 1986). Also, non-sex-typed individuals showed no difference in recall of gender-specific or gender-neutral works, 
whereas sex-typed individuals did. In addition, sextyped individuals organized people into masculine and feminine categories more so than non-sex-typed people.

Bem's gender schematic theory has been criticized for not considering situational variables in its analysis (Mills and Tyrrell, 1983). The main argument here is that not all situations provoke gender schematic processing. Another argument is that there does not need to be a separate gender schema to explain sextyping (Crane and Markus, 1982). Rather, a general self-schema, which includes gender, is adequate to explain sex-typing.

Although these four theories have been widely cited in the gender literature, integration and further development is needed for comprehensive understanding of the perpetuation of accepted gender roles. A major limitation of these gender theories is that they do not answer the question of why parents, teachers, media, and the general culture socialize boys and girls differently. There is little or no recognition or explanation of status and power differences between the sexes. The theories provide descriptions of the sexand gender-typing process but fail to address the relationship between socialization and the gender stratification which is maintained by this 
socialization. The traditional sex-role socialization theories are concerned about the existence of differences but not as much with the evaluation or ranking of the differences.

The conceptual framework that follows, derived from feminist viewpoints, considers issues of inequality in gender arrangements.

Gender Socialization Within a Feminist Framework Valuation of Masculinity and Devaluation of Femininity. According to Henslin (1993), masculine traits are more often valued than feminine traits. Masculine traits are respected more because they are seen as symbolizing success and strength, while femininity is typically valued less because it is thought to represent weakness. Based on these beliefs, females routinely are stereotyped with less socially desirable traits. Moreover, a common male putdown is to refer to another male's behavior or performance as feminine or womanlike. For example, Gilham's (1989) and Eisenhart's (1975) work found marines and drill sergeants to put down male soldiers by comparing their performance to a woman's. The same phenomenon was found to occur in sports (Foley, 1990). In Foley's study (1990), football coaches insulted boys by claiming they 
were wearing skirts, and boys playing basketball were commonly found to put each other down by referring to those who missed baskets as "women" (Stockard and Johnson, 1980). Henslin argues that this name calling is sociologically significant. These remarks represent the devaluation of females and feminine traits in society which works to keep both women and men within the boundaries of sex-role stereotypes.

Once internalized, the consequences of sex-role stereotypes can affect an individual throughout her or his lifetime. Broverman, Broverman, and Clarkson (1972) conducted a study to assess sex-role stereotypic perceptions among adult clinicians. Their findings showed that clinical judgments about the characteristics of healthy individuals differ as a function of sex, and that a perception of a healthy "person" (sex unspecified) resembles the perception of a healthy male more than a healthy female. In this study, males were labeled as more aggressive, independent, objective, dominant, and active than women. Women were stereotyped as more gentle, sensitive, and neat. The researchers concluded that in general, males were perceived as more competent than females. It was also found that more of the traits which were attributed to males were perceived as desirable, whereas the stereotypes attributed to 
females are less likely to be socially desirable. More recent replications and studies have also confirmed these findings (Henslin, 1993).

In general, the literature suggests that boys have more intense "gender-specific" socialization. In comparison to girls, boys receive more pressure to engage in gender-appropriate behavior (Andersen, 1993). Boys also receive more punishment when acting outside of gender-appropriate roles and more praise, while adhering to gender-specific roles (MacCoby and Jacklin, 1974). The literature suggests that girls' sex-role socialization tends to be intensified once they are in their teens where value is placed on sexual identity and finding a mate (Katz, 1979). In other words, the importance of boys learning to be masculine and to not be feminine is emphasized during childhood. The implication here is that masculinity is highly valued. When, however, girls reach the age at which they are expected to begin thinking about eventually finding a husband, the importance of their femininity is emphasized. Here the message seems to be not that femininity is valued per se, but rather it is valued for its usefulness in "catching" a husband. These messages at the micro level parallel gender arrangements at the macro level. 
Social Reproduction of Gender Roles. The ranking of sex differences can also be understood by examining its relationship to the social structure. Differential ranking of genders is pervasive and is reproduced "naturally" as a result of gender differences being incorporated into our reality (Haste, 1994). One can understand how the differential ranking of genders is built into reality by examining societal institutions such as the economy and the polity.

Economy. Women have lower economic status than men as seen by their overrepresentation in the lowest income brackets (Nielsen, 1990). Of people living below the poverty level, 80\% are women (Basow, 1992). Unemployment rates of women are also higher than those of men. A major factor contributing to women's lower economic status is that women have traditionally not been socialized to pursue careers outside of the home and, therefore, are channeled towards temporary or parttime jobs while having limited access to higher paid professions. The masculine stereotype perpetuates the economic institution's preference for professional male employees. Since males are gender stereotyped and thus socialized to be aggressive and achievement oriented, they are typically the sex chosen to obtain power and control in the economic sphere. Basow argues that women 
who break out of the traditional stereotype and elevate their economic status will also enhance their social status generally, and that, therefore, economic status served as the best predictor of equality (1992).

Polity. Politically, women also have limited power. Women represent less than $20 \%$ of all elected offices in the United States (Nielsen, 1990). Since men dominate in the political arena, laws and public policies are constructed and interpreted from a male perspective. Sex-role stereotypes contribute to this unequal division of labor in politics. Stereotypic images of female weakness, irrationality, and emotionality all work against women's political opportunities.

In the United States, few women serve in the judiciary system. In the past 15 years, there have been only been two women appointed to the Supreme Court. As of 1991, only six percent of all members of Congress were women, and less than one-fifth of statewide elected officials and members of state legislatures were female (Reis and Stone, 1992). While only $17 \%$ of the mayors are women, this percentage has increased over the past two decades (the proportion of women mayors in 1971 was 1\%) (Reis and Stone, 1992). It is also the case that nationwide, only 20\% of lawyers are women (Andersen, 
1993). Examination of military officers shows that on the average, women constitute only ten percent of the highest ranked officers (Reis and stone, 1992).

Given the perception of dichotomized gender, representations of sex-role differences are recycled and filtered through all levels of society. Gender stereotypes affect societal institutions and their functioning, and societal functioning also serves to maintain gender stereotypes. However, one limitation of claiming that gender is so deeply embedded in our social structure is that it suggests that gender relations will be resistant to change at the individual level.

The traditional theories of gender socialization tend to ignore the existence of gender stereotypes at both the micro and macro levels of society. More attention needs to be aimed toward linking these levels and examining the interplay between them. Nancy Chodorow (1978) takes a psychoanalytic approach in her efforts to link gender socialization at the micro and macro levels. Chodorow argues that gender socialization at the micro level differs for boys and girls. Girls develop a secure feminine personality by identifying with their mother while also experiencing a recognition of the social rights and privileges that are associated with being a male. Boys, on the other hand, must reject 
and repress the feminine traits that are learned from their mothers at a psychological as well as cultural level to obtain their male identity. This rejection of the feminine leads the boys to define that which is feminine in negative terms and thus devalue traits which are associated with women. Chodorow suggests that this identification process for boys is significant because, due to the relative absence of fathers (particularly as intimate caretakers in children's earliest years), boys must develop a sense of what it is to be masculine through identification with cultural images of masculine models. Exposure to dichotomized gender characteristics at the macro level influences psychological choices at the micro level.

Chodorow argues that this continuing phenomenon of female-dominated mothering of infants and young children is crucial in explaining the secondary status of women at the macro level. Representations at the macro level reflect gender divisions built into the social structure and are internalized by families. Consequently, they are taught to and learned by children. When children accept and adhere to these gender prescriptions, they assume appropriate gender roles and continue to reproduce gender as an asymmetrical social relation. 
Chodorow also argues that the reproduction of gender roles through mothering serves the interests of capitalism in American society. Chodorow suggests that as fathers increasingly became involved in the public and economic sphere, women came to be seen as solely responsible for the domestic sphere. Mothering, her primary domestic role, produces personality characteristics in children necessary for life in a capitalistic society. For example, through a son's separation from his mother, he learns autonomy, individualism, and objectivity--all necessary personality characteristics which are valued and respected. Consequently, the children learn how to survive in a capitalist culture which helps maintain and perpetuate capitalism. In this culture of capitalism, outside the family, men gain economic power. The increase in fathers' power contributes to their children's internalization of males' higher status and social privileges in society. With men continuing to be the dominant sex in the public and economic sphere, society itself takes on a masculine identity, and women's work remains devalued because it is not measurable in the same economic terms. When all of society's institutions reflect the ideologies of capitalism, this masculine-typed society becomes even 
more legitimated and an ideal place for sons to express their own masculinity. In daughters, mothering itself is reproduced. The result is that the psychological personality characteristics necessary for capitalism are reproduced in the next generation. According to Chodorow, the result is that mothering serves as an internal connection to a capitalistic society thus making the link between micro and macro levels of society.

The social reproduction of gender relies on the acceptance of particular ideologies. In U.S. culture, the dominant belief system and the organization of the political economy reflect the belief that those traits associated with maleness are superior to those associated with femaleness.

While Chodorow has taken a psychoanalytic approach in describing the internalization of gender at the micro level, my interest in this research is in the observable beginnings of gender stereotyping by parents. It is not my intent to test Chodorow's or any other theories previously described.

Rather, my research reexamines the existence and nature of the beginning stages of parental gender socialization and the compatibility of this gender socialization with feminist perspectives on the 
valuation and social reproduction of gender. Hopefully, this research can be used to further develop gender socialization theories by shedding more light on parental gender-stereotyping of their infants at the beginning of a socialization process that reinforces the traditional stereotypes that have historically placed a higher value on male traits, ultimately better preparing men for success in the public sphere and perpetuating the reproduction of gender that continues to limit women who may not see themselves nor be seen by others as capable of participation in the economy or polity. This research is to be used in theoretical development as examples of how the sexes are stereotyped and socialized rather than what the consequences are presumed to be. This research can also be used as a starting point for theoretical developments regarding the social reproduction of gender at the micro level of culture. 
CHAPTER III

METHODOLOGY

The literature clearly suggests that, based on their sex, infants are viewed differently by parents. It also appears that parents have different expectations for sons and daughters. The intention of this research was to examine whether or not sex-role stereotyping of infants by parents still occurs, the specific hypothesis being :

That gender stereotyping of infants by parents identified in the literature in the last 20 years still persists 2 decades later despite the increased attention to and literature on gender.

It has been argued that research relating to sexrole issues has been complicated by the terminological awkwardness of the words masculinity and femininity (Spence, 1984). Masculinity and femininity are believed to be the underlying dimensions of personality which distinguish males from females. The awkwardness of the terms is often a result of interchangeably using the terms gender and sex, when in fact, they have separate meanings. Sex refers to the biological and physical 
categories of male and female, whereas gender (masculinity and femininity) refers to the social characteristics that a society considers proper for males and females (Henslin, 1993). Using gender and sex interchangeably can lead to confusion between how females and males are and how they "should" or "ought" to be. It is important to note that it is theoretically possible, but rare, for sex and gendered roles to always be complementary (Nielsen, 1990). Basically, one inherits her or his sex but learns her or his gender. The purpose of this research was to identify perceptions of infants by parents as they do or do not fit with gender stereotypes. By using 24-hour old infants, this research also provides an example of how initial knowledge of the biological difference of sex calls forth expectations of gender.

\section{Sample and Settings}

The sample consisted of 25 parent pairs in each of two hospitals: Memorial Hospital in Yakima, Washington, and Capital Medical Center in Olympia, Washington. Yakima is located in central Washington state, approximately 130 miles east of Seattle and 80 miles south of Wenatchee. Yakima has a population of approximately 55,000, which is about half Caucasian and 
half Hispanic. Yakima's primary commercial products are fruits and agricultural goods. Memorial Hospital is a 217-bed facility with a maternity ward of 30 beds. Labor, delivery, and recovery occurs in 25 of these beds with an average of 15 patients per day. The maternity ward at Memorial has 102 staff members, 14 on duty per shift and an approximate 20 obstetricians who deliver infants.

Capital Medical Center is located in Olympia, the capital of Washington State, and an important commercial center. Olympia is at the southern end of Puget Sound, 60 miles south of Seattle and 190 miles west of Yakima. Olympia's population is approximately 34,000. Capital Medical Center is a 110-bed facility with an average of 70 beds per day filled. The maternity ward includes ten beds, all of which are used for labor, delivery, and recovery. An average day includes five patients, four of whom have given birth. Women's Services at Capital Medical Center has 26 staff members. Staffing fluctuates depending upon number of births, scheduled caesarean sections, and inductions. However, two nurses and one scrub tech are scheduled per shift. When the number of births increases, nurses are called in, as the Women's Service Department has a policy of one-to-one 
care. Approximately ten obstetricians and two midwives deliver infants at Capital Medical Center.

Parents were originally contacted through the cooperation of the Obstetrician Department director, then secondarily with the cooperation of the maternity ward staff. Sample requirements included: 1) the parents were English speaking, 2) the mother and father were cohabitating or married, and 3 ) the birth was uncomplicated and full term.

All parents were required to sign a consent form to allow the interview and release of hospital medical records to the researcher only as they pertained to the birth certificate worksheet. Parents were also informed that they may not receive any direct benefit from participation in the study, and that they were free to withdraw from the study at any time without jeopardizing the care they received in the hospital. Anonymity rights of the subjects were protected by the assignment of a number to each interview packet after medical record information was obtained and recorded onto the interview code form. The purpose of keeping this information anonymous was to protect the child's and parent's personal privacy and identity.

The researcher first checked in with a unit secretary to verify which patients could be interviewed. 
The role of the unit secretary on a maternity ward includes organizing all birth information, fulfilling clerical duties, supplementing physician requests, assisting caesarean sections, and being responsible for bed control.

The delicate situation of approaching new parents was handled by the researcher introducing herself (with mention of her credentials) to potential respondents and also providing a brief description of the study to them. The researcher then asked if this was a comfortable time to talk and subsequently asked for voluntary participation. Fathers who were in the room when the researcher entered were included in the approach. Fathers who were outside the mother's room or arriving at a later time were given the same explanation of intent. The interviews were organized to avoid questioning the mother and father simultaneously. Mothers were asked questions when the fathers were reading instructions and completing the questionnaires and vice versa. The shortest interview lasted 15 minutes and the longest was 55 minutes. An estimated average of time for all interviews was 30 minutes.

For the purpose of this study, 25 parent pairs from each hospital were determined to be a reasonable and manageable sample size. Choosing two hospitals in which 
to conduct interviews was an intentional effort to broaden the sample.

Initially the intention was to compare the data from the two hospitals. However, after looking at the data from both samples, the results were combined as no notable differences were found between the two data sets. So for the purpose of analysis, the data gathered from each hospital have been treated as one set.

Although all 25 mothers in each hospital were interviewed, only a total of 28 fathers were interviewed. In the new-parent population, fathers were difficult to locate. The mothers commonly explained that the father's absence was due to the fact that he was tending to other children, working, or "running" errands. The researcher always asked the mother when she anticipated the father would return to the hospital so a second attempt could be made to contact the father within the same day of interviewing the mother. However, fathers were often still not available for the interview. Of the mothers and fathers who were approached for an interview, 100 percent agreed to participate. 


\section{Measures}

Using an open-ended question and an $18 \mathrm{bi}$-polar adjective semantic differential scale, Rubin found in 1974 that sex-role stereotypes of infants by parents are expressed within the first 24 hours of birth. Parents were found to respond stereotypically to their infants, perceiving daughters as littler, finer-featured, and more inattentive than sons, even though the babies did not differ significantly in terms of birth length, weight, or Apgar scores. Rubin's original study has served as a base for subsequent research on the issue of sex-role stereotyping of infants by parents. Replicating his basic research was an attempt to examine the existence of stereotyping two decades after the original study was published. Questions relating to the importance of recognition of babies' sex and preference for gender-specific or gender-neutral clothing and toys were added by the researcher because other genderrelated research has found these issues to be relevant to sex-role stereotyping of infants by parents.

Rubin's original interview guide and a series of open-ended questions constructed by the researcher were used to assess parents sex-role stereotyping of their newborns. 
The subjects were first asked an open-ended question to, "Please describe your baby as you would to a close friend or relative." Probes were sometimes necessary to assist the subject in completing the answer. For example, the subjects were told to pretend they were talking to a friend on the phone who could not see the baby but wanted a description of her/him. The responses were recorded by the researcher onto the interview guide. The data were used to look for patterns of physical and personality-related responses. Analysis of the open-ended responses yielded 16 categories of descriptions (See Figure 1). These responses were coded a "1" if the parent mentioned the descriptor and "O" if they did not. 
FIGURE 1

MOST COMMON OPEN-ENDED DESCRIPTORS USED BY PARENTS TOWARD NEWBORN

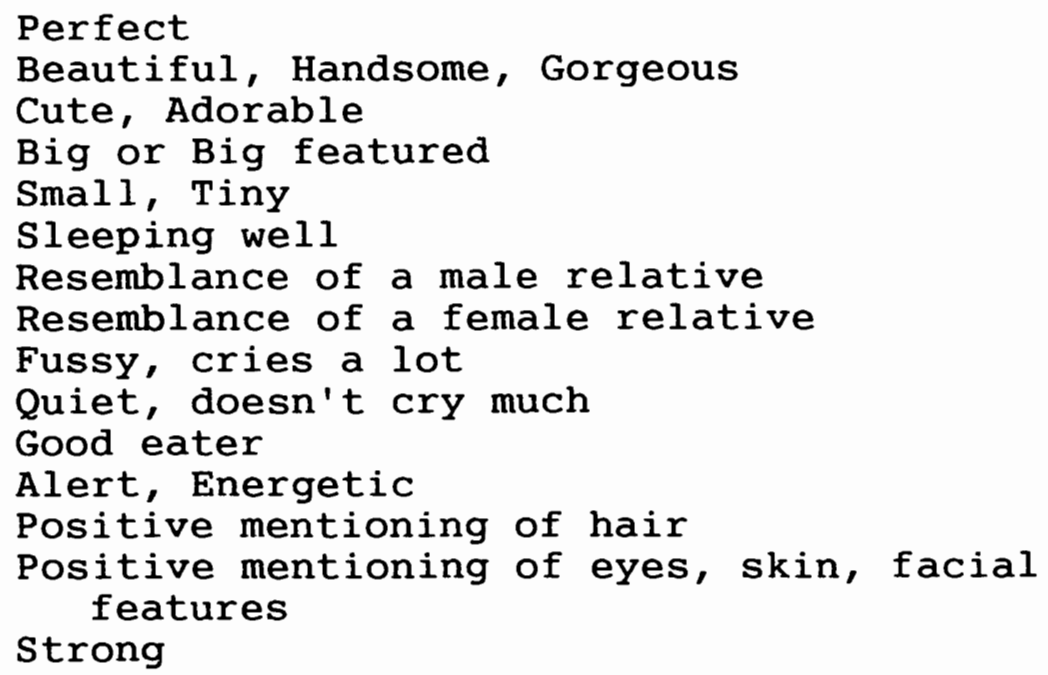

The semantic differential scale was then

administered to the subjects. This scale included gender attributes which are traditionally associated with masculinity or femininity. Subjects were asked to respond to the scale provided to them by the researcher. The following instructions were given to the subject: place an " $x$ " along the continuum which best describes your baby; the more a word describes the baby, the closer the " $x$ " should be to that word. See Figure 2 for adjectives included on the scale. 
FIGURE 2

SEMANTIC DIFFERENTIAL SCALE

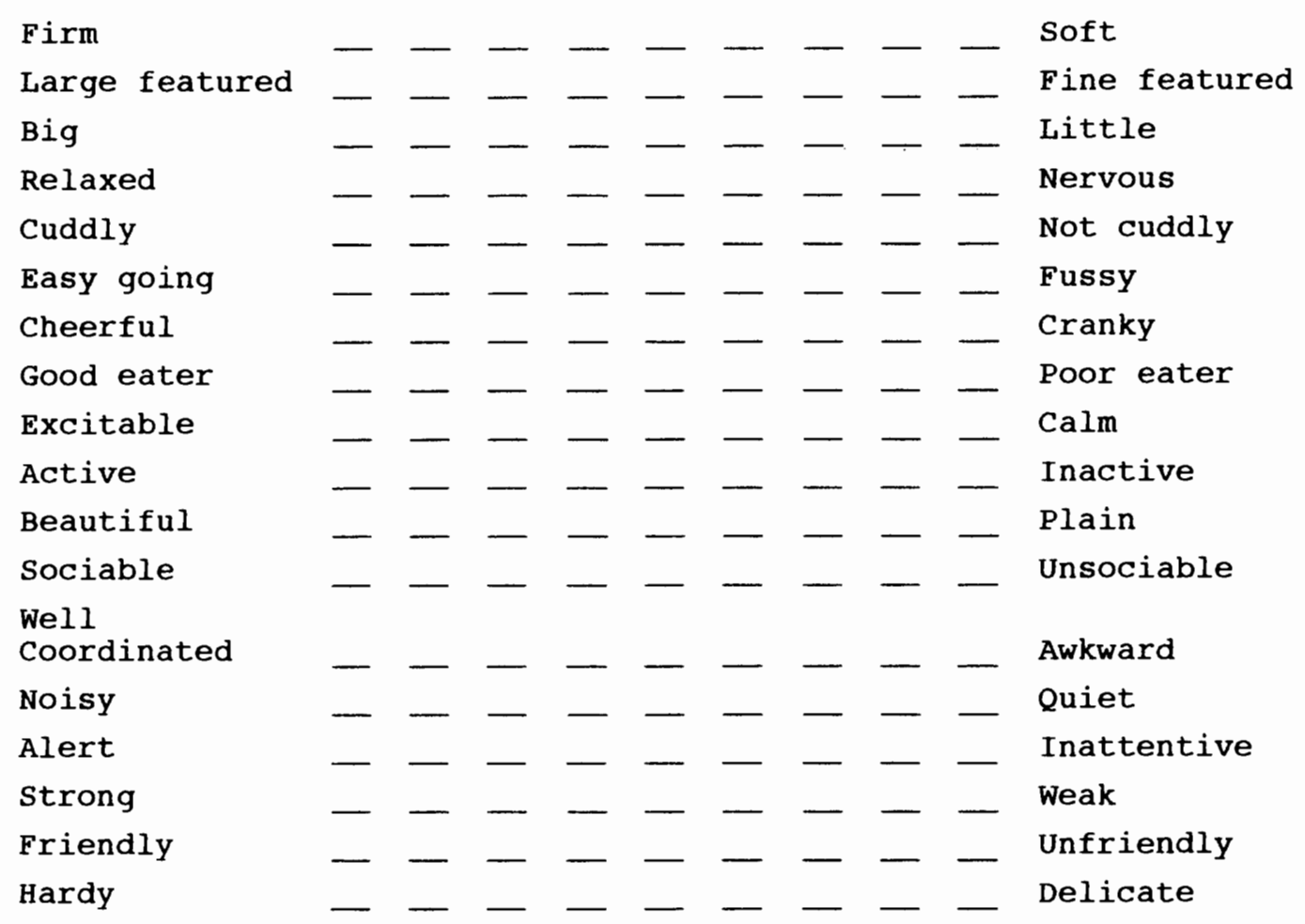

Means were figured for all sets of adjectives and calculated on sex of parents by sex of infant. The larger the mean, the greater the rated presence of the attribute denoted by the second (right-hand) adjective in each pair.

Parents were also asked a short set of questions that related to the importance they attributed to their toy and clothing preferences for their baby and to others recognizing their baby's sex (see Figure 3 ). Questions 1 and 2 were coded according to a gender- 
neutral or gender-specific response: "O" represented gender-neutral, while "1" represented gender-specific. Responses to question three fell into one of three categories: important for the infant, important for the parent, or important because of what others will think. Responses were coded "0"; $1 "$, and "2" respectively. The data were coded according to the degree of importance to parents and parents' preference for gender-specific or gender-neutral toy and clothing choices for their newborn by sex of infant. The degree of importance ranged from zero to four, with zero representing a parental response of "not at all important" and four representing a parental response of "very important".

FIGURE 3

QUESTIONS ASKED OF PARENTS IN REGARD TO TOY AND CLOTHING PREFERENCE

1. How will you dress your infant? Do you have clothing preferences for her/him? What is she/he going home in from the hospital?

2. What type of toys will your infant play with?

3. Why have you chosen these toys?

4. How important is it to you that others recognize right away whether your baby is a boy or a girl? 
Objective data were also gathered from the birth certificate worksheet. This information included parents' age, education, race, and child's race, birth order, weight, and Apgar scores (two scores assigned five and ten minutes postpartum to represent physician ratings of infants' color, muscle tonicity, reflex, heart, and respiratory rates). These data were collected with the cooperation of the supervisor in Medical Records at both hospitals. The demographic data were gathered primarily for descriptive purposes.

\section{Data Analysis}

Codes for demographic data and the semantic differential scale were determined prior to the interviews. A final coding book was constructed after all subjects had been interviewed, and the responses to the open-ended questions were examined by the researcher. Open-ended descriptions were included in the statistical analysis if the responses appeared in three or more of the coding forms. After the interviews were completed, the responses were coded on the interview guide then transferred to graph paper.

The data were entered on a personal computer using EXCEL, then transferred to SPSS-X where analyses were conducted. Frequencies were initially obtained on all 
the variables for the purpose of describing the sample and examining the nature and range of responses and the demographic data. After frequencies were analyzed, crosstabulations were run on parents' open-ended descriptions of their infants and preference of genderspecific vs. gender-neutral toy and clothing, by sex of parent and sex of infant. 
CHAPTER IV

\section{RESULTS}

\section{Description of the Sample}

Of the 50 pairs, $100 \%$ of the mothers and $56 \%$ of the fathers were interviewed (at the hospital). Of the fathers who were interviewed, $70 \%$ had boys and $30 \%$ had girls. Descriptive data on subjects' education, age, and race were given in Tables $1-4$. Table 1 shows sex of infant and where the interview took place. Table 2 shows that parents' education is distributed across a wide range (from less than high school to advanced degrees), with fathers most commonly reporting "high school graduate" as their highest level of education. Mothers, however, were most likely to report "some college" as their highest level of completed education. 
TABLE 1

SEX OF BABY BY HOSPITAL

Memorial

Hospital

Capital

Medical

Center

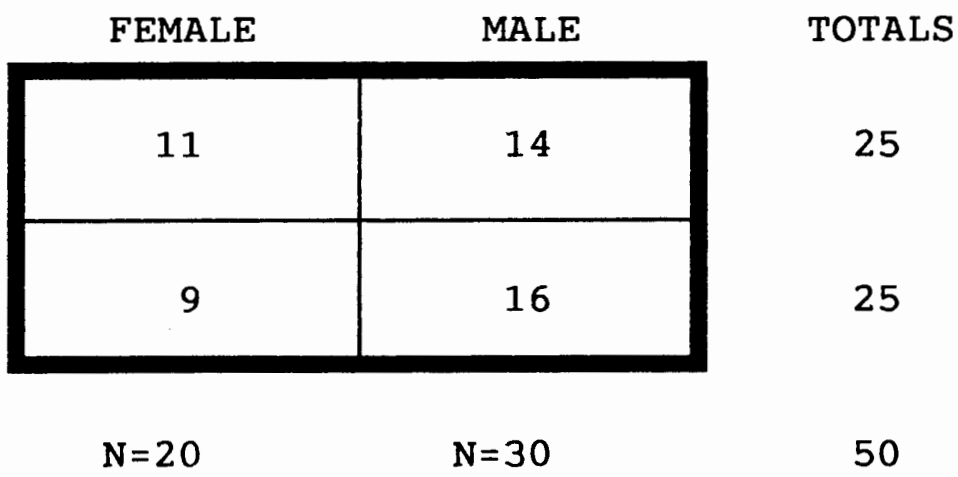

TABLE 2

PARENTS' EDUCATION, BY PERCENT

Level of Education

Less than High School

High School Graduate

Some College

College Graduate

Advanced Degree

Unknown

TOTALS
Mothers

$(\mathrm{N}=50)$

$14 \%$

$24 \%$

$28 \%$

8 음

$3 \%$

$23 \%$

$100 \%$
Fathers

$(\mathrm{N}=28)$

Table 3 displays a distribution of parents' ages, showing that $36 \%$ of the fathers were between the ages of 26 and 30 years old, with 29 years old being the mode. Mothers tended to be younger than fathers; $40 \%$ of them 
were between the ages of 21 and 25 years old, with the mode being 24 years old.

TABLE 3

PARENTS ' AGE, BY PERCENT

\begin{tabular}{lrr}
\hline Age in Years & $\frac{\text { Mothers }}{(\mathrm{N}=50)}$ & $\frac{\text { Fathers }}{(\mathrm{N}=28)}$ \\
$17-20$ & $12 \%$ & $4 \%$ \\
$21-25$ & $40 \%$ & $22 \%$ \\
$26-30$ & $30 \%$ & $36 \%$ \\
$31-35$ & $12 \%$ & $20 \%$ \\
36 \& Older & $6 \%$ & $8 \%$ \\
TOTALS & $100 \%$ & $100 \%$ \\
\hline
\end{tabular}

Data regarding the subjects' race were also gathered from the birth certificate worksheet. Table 4 shows that 70 percent of the fathers and 68 percent of the mothers were white. Subjects' race was also divided into Hispanic, American Indian, and Asian. Although the number of white subjects is comparable to their percentage in the U.S. population, Hispanics were slightly and American Indians were substantially overrepresented relative to their numbers in the U.S. population. Furthermore, there is no representation of African Americans in the sample (1994 census data 
indicates that Hispanics represent 9.0\%, American Indians represent $.8 \%$, and African Americans represent $12.1 \%$ of the United State population (Schlesinger, 1993)).

TABLE 4

PARENTS' RACE, BY PERCENT

\begin{tabular}{lrr}
\hline Race & $\frac{\text { Mothers }}{(\mathrm{N}=50)}$ & $\frac{\text { Fathers }}{(\mathrm{N}=28)}$ \\
White & $68 \%$ & $70 \%$ \\
Hispanic & $18 \%$ & $8 \%$ \\
American Indian & $10 \%$ & $10 \%$ \\
Asian & $4 \%$ & $2 \%$ \\
Unknown & $0 \%$ & $10 \%$ \\
TOTALS & $100 \%$ & $100 \%$ \\
& & \\
\hline
\end{tabular}

Of the 50 newborn infants, $60 \%$ were boys and $40 \%$ were girls. There was a relatively equal number of primiparous births and "other than first born births", $42 \%$ and $58 \%$ respectively. Table 5 shows that the newborns' race, followed a similar pattern as the parents' race, with approximately three-quarters of the infants being identified by their parents as white. of note here is that race identification may be problematic among newborns, as parents have the freedom to identify 
their newborn's race. In fact, a slightly higher percentage of infants than parents were identified as white in this study.

TABLE 5

NEWBORNS' RACE, BY PERCENT

Race

Percentage

$\frac{\text { of Newborns }}{(N=50)}$

White

$74 \%$

Hispanic

$10 \%$

American Indian

$10 \%$

Asian

$4 \%$

TOTALS

$100 \%$

\section{Frequencies}

Parents were asked to: "Please describe your baby as you would to a close relative or friend." Table 6 shows the 16 most common responses stated by parents and the number of times that each sex was actually described by that adjective. Due to the small numbers in each cell, mothers' and fathers' responses were combined. However, it is interesting to note that when analyzing the data separately, fathers described eight sons as 
alert, energetic, or active, whereas none of them described their daughters with these adjectives. As one father said, "My son's personality is great; he is so energetic, happy, and alert to the environment." Five fathers also described their sons as perfect, whereas not one father described his daughter as perfect. One father exclaimed how perfect his son was, "Just like his older brothers" (although he failed to mention his newborn's older sister, who was present). Another father told the researcher that his son was, "His best work and a truly perfect baby." Again, this father failed to acknowledge his "work" on the infant's four other siblings, half of whom were girls.

When analyzing mothers' descriptions of their newborns, it was apparent that they also described their sons as alert, energetic, active, and perfect more often than their daughters. Mothers tended to describe their newborn boys and girls as equally sleeping well; however, fathers with sons tended to describe their newborn as sleeping well three time more often than did fathers with daughters.

When considering both parents' descriptions, it is interesting to note that there were only four categories in which newborn baby girls were described more often than newborn baby boys, those categories being: small 
or tiny, resemblance of a female relative, being a good eater, and fussy or cries a lot.

$$
\text { TABLE } 6
$$

PARENTS ' OPEN-ENDED DESCRIPTIONS

BY INFANT SEX, FREQUENCIES, AND PERCENTAGES

Description

Perfect

Beautiful, handsome, gorgeous

Cute, adorable

Big or big featured

Small or tiny

sleeping well

Resemblance of male relative

Resemblance of female relative

Fussy, cries a lot

Quiet, good baby, doesn't cry much

Good eater

Alert, energetic, active

Positive mention of hair

Positive mention of eyes, skins, or facial features

Healthy

strong

Sons

Daughters

Frequency $\quad \frac{\text { Percent }}{(N=30)} \quad$ Frequency $\quad \frac{\text { Percent }}{(N=20)}$

\begin{tabular}{|c|c|c|c|}
\hline 7 & $23 \%$ & 1 & $5 \frac{\circ}{2}$ \\
\hline 13 & $43 \%$ & 9 & $45 \frac{\circ}{2}$ \\
\hline 15 & $50 \%$ & 10 & $50 \%$ \\
\hline 12 & $40 \%$ & 4 & $20 \%$ \\
\hline 3 & $10 \%$ & 4 & $20 \%$ \\
\hline 7 & $23 \%$ & 4 & $23 \%$ \\
\hline 18 & $60 \%$ & 7 & $35 \%$ \\
\hline 3 & $10 \%$ & 4 & $20 \%$ \\
\hline 2 & $7 \%$ & 4 & $20 \%$ \\
\hline 25 & $83 \%$ & 12 & $60 \%$ \\
\hline 3 & $10 \%$ & 4 & $20 \%$ \\
\hline 14 & $47 \%$ & 2 & $10 \%$ \\
\hline 18 & $60 \%$ & 15 & $75 \%$ \\
\hline 10 & $33 \%$ & 9 & $45 \%$ \\
\hline 7 & $23 \%$ & 6 & $30 \%$ \\
\hline 3 & $10 \%$ & 0 & $0 \%$ \\
\hline
\end{tabular}


Examining the percentage of sons and daughters who were described by their parents with these characteristics provides another look at the findings.

Although all of the birth weights of newborns in this sample were within a normal range, $40 \%$ of the sons were described as big or big featured, while only $20 \%$ of the newborn girls were described this way. Several fathers illustrated their belief that their son was big by showing the researcher their son's "basketball hands" or explaining his "football legs". One mother even claimed that because of her son's size, he would be "shooting hoops" by his first birthday. It is important to recognize that although not every parent described their son in this way, not one perceived their daughter to have sports-related capabilities due to her big size or size of features. These descriptions and expectations by parents are representative of sex-role stereotypic beliefs that males are bigger and have bigger features; therefore, they have the skills necessary to play sports.

Just as sons were described as bigger, daughters were described as small and tiny more often than were boys, $20 \%$ and $10 \%$ respectively. One mother explained, 
"She's nothing like her brother; she's so tiny and small, and just beautiful."

The stereotypic belief that girls possess physically attractive traits was reflected in the findings. Forty-five percent of the newborn girls were described as beautiful or gorgeous. Although this is similar to the percentage of descriptions of newborn boys as physically attractive, it was made very clear to the researcher that several newborns must be a girl, "since she was so beautiful". As one father described his daughter, "I was personally so overtaken because she's so beautiful." Another mother told the researcher, "I can't believe we did that, but I knew if it was a girl she'd be beautiful."

Sons were described as resembling a male relative $60 \%$ of the time, compared with resembling a female relative only $10 \%$ of the time. Not only did one mother describe her son as "looking like his daddy", she also said that, "He sounds like his daddy, acts like his daddy, and even eats like his daddy." Based on the proportion of descriptors by parents, the impression was that it is more acceptable for a daughter to resemble a male relative than it is for a son to resemble a female relative. This is supported by the finding that $35 \%$ of the daughters were described as resembling a male 
relative, whereas only $10 \%$ of the sons were described as resembling a female relative. This may be an example of boys' stricter socialization towards masculinity and an example of girls' greater latitude in crossing over genders. Parents also expressed this difference by describing their daughter as "looking like her brothers" or "father" more often than describing their son as resembling sisters or mothers.

Other major differences in descriptions of the two sexes included the descriptors "fussy" and "cries a lot" and "alert, energetic, and active". In regard to newborns being described as fussy or cries a lot, $20 \%$ of the daughters were described with these adjectives, while only $7 \%$ of the sons were. Of newborn boys, $47 \%$ were described as alert, energetic, or active compared to $10 \%$ of the girls. Several parents made comments referring to their newborn son as being alert, energetic, or active "just like his older brothers" or "just like his older cousins". One mother, who described her newborn daughter as energetic and active, explained that she "thought the baby was going to be a boy because it was so active and energetic during the pregnancy!"

In terms of mentioning positive comments about newborns' physical attributes such as hair, eyes, skin, 
or facial features, daughters received the most descriptions in both categories, $75 \%$ and $45 \%$ respectively.

Strength of infants was only recognized and described in newborn sons. While only $10 \%(\mathrm{~N}=3)$ of the sons in this study were described as being strong, it is interesting to note that none of the daughters were described as possessing strength by either mothers or fathers. One father even insisted that the researcher "feel how strong my son's grip is."

Both sexes were described relatively similarly in terms of being healthy: $23 \%$ of the sons and $30 \%$ of the daughters. The only descriptions for which sons and daughters received equal numbers of comments were "cute or adorable" and "sleeps well".

Although these differences in descriptions were not tested for significance due to the size and nonrandomness of the sample, it is important to note the clear differences in parents' descriptions of their sons versus their daughters within 24 hours of birth. Parents most often used descriptions which represented the sex-role stereotypes that have been assigned to each gender solely on the basis of sex.

Table 7 provides parents' mean ratings (on a scale from 1-9) of their infant for each of the adjective 
pairs on Rubin's original semantic differential scale. Several points can be drawn from Table 7. Among the most apparent differences in the mean rating of the adjectives is fathers' perceptions of their sons and daughters regarding "big-little". Fathers' average rating of their sons on this variable was 4.06 ( $1=\mathrm{big}$, 9=little), while ratings of their daughters on the same adjective pair was over 2 points higher. Mothers also perceived their sons to be bigger; however, the difference is not as large: sons were rated at a mean of 5.13 and daughters rated a mean of 6.40. This finding is similar to those from the open-ended questions: $40 \%$ of newborn boys were described as big or big featured by their parents, while only $20 \%$ of the daughters were.

Another clear difference was noted in regard to the "hardy-delicate" adjective pair. Fathers had a greater tendency to perceive their sons as hardy (mean=4.12) rather than delicate, whereas fathers' perception of daughters and mothers' perception of sons and daughters on the "hardy-delicate" scale are all in the 5.00 range. Mothers and fathers agreed in their perceptions of their newborn as "large featured-fine featured". They perceived sons as closer to the large-featured side of the scale and daughters possessing finer features. The 
largest distinction on the "large featured-fine featured" scale was the mothers' rating of daughters' features as fine $(\operatorname{mean}=6.55)$. Both parents also tended to rate their sons as more relaxed and their daughters as more nervous on the "relaxed-nervous" adjective pair. Again, referring to Table 6 , this is in agreement with parents' open-ended descriptions of their newborns where $20 \%$ of the daughters and $7 \%$ of the sons were labeled fussy.

Analysis of the findings from the semantic differential scale shows that fathers' perceptions of newborn daughters tended to be more extreme than their perceptions of sons or than mothers' perceptions of either sex. This is true regarding fathers' perception of their daughters as: awkward, inattentive, inactive, cranky, fussy, weak, and nervous. Exceptions to this pattern were on the following adjective pairs: large featured-fine featured, big-little, and noisy-quiet. It is important to recognize that fathers' perceptions on these "exceptions" still represent stereotypic images (as did those of the mother), but were not more extreme than the mothers' (for a comparison of Rubin's findings on the semantic differential scale with the current research, see Appendix E, on page 94. 
TABLE 7

MEAN RATINGS ON SEMANTIC DIFFERENTIAL SCALE BY SEX OF PARENT (M-F)* AND SEX OF INFANTS (S-D)*

\begin{tabular}{|c|c|c|c|c|}
\hline Adjectives & $\underline{M-S}$ & $\underline{M-D}$ & $\underline{\mathrm{F}-\mathrm{S}}$ & $\underline{F-D}$ \\
\hline Firm-Soft & $7.13 * *$ & 6.85 & 6.33 & 5.55 \\
\hline $\begin{array}{l}\text { Large Featured-Fine } \\
\text { Featured }\end{array}$ & 5.80 & 6.55 & 4.71 & 5.50 \\
\hline Big-Little & 5.13 & 6.40 & 4.06 & 6.30 \\
\hline Relaxed-Nervous & 2.37 & 3.45 & 2.82 & 3.60 \\
\hline Cuddly-Not Cuddly & 1.40 & 1.90 & 1.65 & 2.30 \\
\hline Easy Going-Fussy & 2.80 & 3.50 & 2.71 & 4.90 \\
\hline Cheerful-Cranky & 3.03 & 3.35 & 2.82 & 4.20 \\
\hline Good Eater-Poor Eater & 2.53 & 2.85 & 2.82 & 3.50 \\
\hline Excitable-Calm & 5.86 & 6.20 & 6.41 & 6.80 \\
\hline Active-Inactive & 3.40 & 3.65 & 3.53 & 4.40 \\
\hline Beautiful-Plain & 1.33 & 2.05 & 1.35 & 3.30 \\
\hline Sociable-Unsociable & 2.73 & 3.15 & 2.65 & 5.10 \\
\hline $\begin{array}{l}\text { Well Coordinated- } \\
\text { Awkward }\end{array}$ & 3.30 & 3.40 & 3.88 & 4.80 \\
\hline Noisy-Quiet & 6.10 & 6.05 & 5.88 & 6.00 \\
\hline Alert-Inattentive & 2.20 & 3.00 & 2.29 & 3.40 \\
\hline Strong-Weak & 2.13 & 2.80 & 2.59 & 3.30 \\
\hline Friendly-Unfriendly & 2.10 & 2.30 & 2.36 & 3.57 \\
\hline Hardy-Delicate & 5.50 & 5.65 & 4.12 & 4.90 \\
\hline
\end{tabular}

* M=Mother, $F=$ Father, $S=$ Son, $D=$ Daughter

* The larger the mean, the greater the rated adjective on the second (right adjective) of each pair. 
Table 8 shows the percentage of responses received from parents who mentioned preference of clothing and toy choices for their infants. These figures have been computed in proportion to the number of parents who were interviewed for each sex. One of the strongest findings here is that no parents suggested that their newborn daughter should have gender-neutral toys now, but gender-specific toys later, whereas $16 \%$ of the parents preferred this pattern for their sons. This was explained to the researcher in the following statements: "Oh, he can play with whatever he wants for the first couple of years, but then he'd get too confused playing with girl things," or "I don't think it would hurt him to play with his sisters' toys at first, but I don't want him to turn out feminine." Several fathers said that, "My son will not play with dolls or Barbies!" In contrast, the most frequent comment of mothers is exemplified in the following statement: "I think it is good for him to play with dolls and trucks; it makes him more well-rounded and caring." Table 8 also shows that parents mentioned gender-appropriate clothing for their son more often than for their daughter, $58 \%$ and $42 \%$ respectively. One mother who gave birth to a boy stated that, "My husband bought pink diapers on sale, but now I will have to throw them away." Parents of newborn sons 
were more likely than parents of newborn daughters to mention clothing or toy preferences at all. Parents gave the impression that they were particularly concerned with toys for sons, making comments such as, "I want him to have a lot of good toys so his skills are good later on." of those parents who preferred genderspecific toys, 25\% more had sons than daughters. Table 8 tends to follow a stereotypic pattern; the only category in which parents of daughters had a higher response was in regard to gender-neutral toys. Parents of sons, however, all were more likely to mention gender-appropriate clothing, gender-specific toys, and neutral toys now, but specific toys later. 
TABLE 8

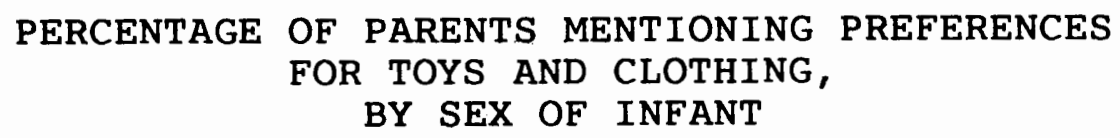

\section{Type Mentioned}

Gender-Appropriate
Clothing

Gender-Specific Toys

Gender-Neutral Toys

Neutral Toys Now,

Specific Later
Parents of

$\frac{\text { Parents of Sons }}{(N=45 *)} \frac{\text { Daughters }}{(\mathrm{N}=25)}$

$58 \%$

$42 \%$

$16 \%$

$12 \%$

$68 \%$

$88 \%$

$16 \%$

$0 \%$

* Percentages are based upon number of parents who mentioned clothing or toy choices. Of the total sample of 78,8 fathers chose not to answer this question.

Judging from the percentages in Table 8, parents' preference for gender-neutral toys is greater than their preference for gender-specific toys for both sexes. Of those parents who did prefer gender-specific toys for their infants, all explained that it would confuse the infant too much to allow her or him to play with "other" toys.

Table 9 shows parents' responses to the question, "How important is it to you that others recognize the sex of your baby right away?" The distribution of 
responses tends to be skewed toward parents not attributing a great deal of importance to others recognizing their baby's sex, with only $7 \%$ of parents of sons and $16 \%$ of parents of daughters responding that it was very important to have others recognize their baby's sex .

\section{TABLE 9}

PERCENTAGE OF PARENTS ATTRIBUTING DIFFERENT LEVELS OF IMPORTANCE TO "OTHERS RECOGNIZING BABY'S SEX RIGHT AWAY", BY SEX OF INFANT

\section{Level of Importance}

Not At All Important

Not Important

Somewhat Important

Important

Very Important

\begin{tabular}{|c|c|}
\hline Parents of Sons & $\begin{array}{l}\text { Parents of } \\
\text { Daughters }\end{array}$ \\
\hline$(\mathrm{N}=45 *)$ & $(N=25)$ \\
\hline $44 \%$ & $32 \%$ \\
\hline $24 \%$ & $24 \%$ \\
\hline $9 \%$ & $8 \%$ \\
\hline $16 \%$ & $20 \%$ \\
\hline $7 \%$ & $16 \%$ \\
\hline
\end{tabular}

* Number of parents is based upon parents who specifically answered this question. Of the total sample of 78,8 fathers chose not to answer this question.

Although parents described and perceived their sons and daughters differently and had some gender preferences for their clothing and toys, they seemed somewhat less concerned about whether or not others 
think their baby is a girl or boy. Parents often commented that, "It's okay when they can't tell I have a daughter, but I always correct them," or that "It doesn't matter so much what others think, but it's important for me and his identity, too."

\section{Summary}

In recent years, there has been increased attention toward stereotyping on the basis of sex. This study is supportive of Rubin's (1974) original findings: sexrole stereotyping by parents does occur within the first 24 hours of life. According to the data gathered in this study, the phenomenon of sex-role stereotyping has not changed in spite of increased literature on and attention to the restrictions and limitations placed on individuals due to gender stereotyping (Rubin's findings in regard to the semantic differential scale can be found in Appendix E for comparison).

Overall, parents' descriptions of their sons and daughters show that sons were more likely to be described as perfect, big or big featured, strong, and energetic. Daughters, however, were most likely to be described as small or weak and by their physical attributes, e.g. eyes, skin, or facial features. Parents of sons were more likely than parents of 
daughters to mention a preference for gender-specific clothing or toys. Infant sex did not appear to make a difference in the importance that parents attributed to others recognizing their baby's sex. 


\section{CHAPTER V \\ DISCUSSION AND CONCLUSIONS}

The findings in this study are consistent with the prior research in that infants are still stereotyped by parents on the basis of sex, despite the increased attention to and literature on gender. The results of this study can be used as a current example of the nature of sex-role stereotyping and gender socialization and may also be useful for theoretical developments in this area.

\section{Comparison of Prior and Current Findings}

Interviewing parents 24 hours postpartum showed the observable beginnings of gender socialization. Sex-role stereotypes were applied to newborn infants on the basis of sex; one implication of this finding is that sex-role stereotypes will more than likely serve as a dominant and primary source of identity in early socialization. Findings from this research are similar to the patterns found in Sweeney and Bradbard's (1987) study. In the current research, parents of sons were more likely to describe their infants as alert, energetic, and active than were parents of daughters; this is consistent with 
Sweeney and Bradbard (1987) who found that parents even associated strong fetal activity with the belief that the fetus would be a son.

The finding that parents most often described their sons as being "strong and hardy" and their daughters as "delicate and tiny" is consistent with Seavey's (1975) findings where parents defined daughters as more fragile and soft, while sons were labeled strong.

Sons were not only more likely to be described in terms of bigness and bigness of features, but also in association with sports-related capabilities. As a result of early gender socialization, gender-specific activities and abilities are reinforced in children's developmental years and possibly throughout their lives. For example, Lever (1978) found in her analysis of play diaries that boys were more likely than girls to define activities as games. And, Rheingold and Cook's (1975) research showed that boys' rooms were more likely to contain sports equipment, while girls' rooms commonly had dolls in them. In the current research, daughters were never described as having sports-related capabilities. Rather, they were more likely to be described as awkward, unsociable, and inattentive-hardly sports-specific related skills! 
Another implication of asymmetrical expectations for the sexes is that girls may lose out on the activities which teach team work, competition, and strategy--all skills which could potentially allow more flexibility in determining roles and future goals. Another potential outcome of parents' beliefs that boys and girls are so different, even at birth, is that they will treat them accordingly, especially in regard to activities and skills. The result may be a selffulfilling prophecy where one behaves on the basis of an assumption that is empirically false, but the behavior then "causes" it to become true.

The finding that $16 \%$ of the parents with sons preferred gender-neutral toys now, but gender-specific ones later is consistent with the literature that suggests that parents are more concerned with oppositesex toy choices for boys than girls (Fling and Manosevitz, 1972; Lansky, 1963). In fact, parents with daughters never mentioned a preference for genderneutral toys now, but specific ones later! It appears that some parents had a notion of a "two year" marker at which time their son had to be given only masculinetyped toys or his identity as a male would be threatened. Twenty-five percent more of the parents of sons than the parents of daughters preferred that their 
infants have gender-specific toys. When looking at the frequency of toy and clothing preferences which were mentioned as a whole, it is interesting that the only category in which the parents of daughters gave more responses was gender-neutral toys. The parents of sons more frequently mentioned gender-specific clothing, gender-specific toys, and of course, gender-neutral toys now, but specific toys "later". Ultimately, it may be that these sons will have less latitude in crossing over gender-typed play and activities. This is compatible with the findings of Andersen (1993) that girls playing with boy groups (and being a tomboy) is more acceptable than boys playing with girl groups (and being a sissy). The data from this study are also consistent with Basow (1992), who argues that some parents have especially negative responses to their sons playing with femalerelated toys.

Another example of sons having less latitude than daughters is the finding in this study in regard to the baby's resemblance of relatives. Parents were more likely to describe their daughters as resembling a male relative than their sons resembling a female relative. Sons were almost exclusively described as resembling a male relative. 
A consequence of sex-role stereotyping for males is that they may receive more intense socialization pressures and as a result, exaggerate more masculine ways and repress the feminine. Another implication of males' stricter gender socialization may be seen later in life when "feminine" traits such as nurturant and expressive capabilities are poorly developed.

For females, the consequences of sex-role stereotyping may include their orientation toward solely a maternal role. Society may, in fact, consider her to be lacking the skills necessary to succeed in the labor market or political arenas since these are both typically dominated by masculine values and patterns. Basow (1992) argues that the extent to which females have developed according to the traditional stereotype places them at a distinct disadvantage in relation to career development and in the labor force as a whole. Fathers in this study tended to be more extreme than mothers in their descriptions and perceptions of both sons and daughters. Rubin (1974) also found that fathers were more extreme in their ratings of both sons and daughters. The tendency of fathers to perceive their infants in more stereotypically extreme ways was explained by Rubin as a consequence of fathers' limited contact with their infants within the first 24 hours of 
birth. If this suggestion is true, then the data in this study should have shown changes in fathers' perceptions as a result of their increased contact with and exposure to their newborns over the last 20 years. In this research, fathers were able to participate in the labor process and also hold their newborn more than during the era when Rubin completed his study. However, since fathers still appear to stereotype their infants more than mothers do, the real cause may be due to other social factors, such as men's own rigid masculineoriented gender socialization whereby they have internalized the concept that gender boundaries are strict and definite. This, in turn, contributes to a father simply reproducing sex-role stereotypes in his own child.

Daughters were most likely to receive descriptors mentioning their physical attractiveness, such as their eyes, skin, hair, or facial features. One interpretation of this finding is that females' attractiveness is deemed more important than their intrinsic characteristics. This is also consistent with Katz's (1979) suggestion that value is placed on women's physical appearance to assure that they can find a mate later in life. An implication of this is that women may continue to be judged and stereotyped on their extrinsic 
characteristics throughout their life while their intrinsic qualities remain unnoticed.

\section{Conceptual Discussion}

Henslin (1993) argues that masculine traits are valued more than feminine traits. The sons in this study were more likely to be described with the valued masculine-associated traits than with feminine traits. For example, sons more often than daughters were labeled or perceived as: strong, hardy, perfect, and sociable. Boys then are more likely to be perceived as having the desirable personality characteristics. It is also interesting that of the $28 \%$ of the fathers who were present during the interviewing process, $70 \%$ of them had sons. One interpretation of this finding is that fathers were more likely to be at the hospital if the newborn was a son. Again, this would strengthen the argument that males are valued more.

This gender differentiation reinforces the gender hierarchy, where in American society, females are viewed as the subordinate or second sex. Stereotyped in this way, women may continuously be ruled out as capable of fulfilling potential professional and political careers. If new generations do not see females in high status and power-related positions, the early socialization is 
confirmed. In a gender-stereotypic culture such as ours, it is within the family that gender messages are passed from generation to generation. The reproduction of sex-role stereotypes in the family both encourages and is encouraged by the overrepresentation of males in power at the macro level of society. Societal institutions such as the economy, polity, and the law are dominated by a relatively small number of men, giving the impression that only males (and actually a select group of males) are capable of obtaining and maintaining these positions.

Chodorow's (1978) suggestion that the reproduction of gender at the micro level is linked to political and economic needs and interests at the macro level is a strong argument, and her work warrants further consideration and empirical study.

\section{Limitations of the study}

Further research on this topic needs to be inclusive of all races as it would be inappropriate to assume that the patterns of whites holds true for other races. It would also be worthwhile to obtain a sample with more individuals from each educational level so that inferences could be drawn in regard to the level of parental stereotyping in relation to their educational 
attainment. Further research on this topic should seek a larger sample from various demographic areas to increase the validity of inferences made. A follow-up study with the parents and newborns (of this study) to assess actual infant behavior and differences, if any, in parental expectations would provide more empirical information on the consequences of sex-role stereotyping. Other social characteristics of parents, such as their gender orientation or religious affiliation, in relation to their expectations and descriptions of their children, warrant further consideration.

\section{Concluding Comments}

In order to eliminate sex-role stereotypes, they must be looked at from both macro and micro perspectives. This is also necessary to consider the nature of stereotypes: once believed, stereotypes are confirmed and reinforced whenever someone behaves in the expected way. So, to challenge stereotypes, future generations need to be reached before they learn them, meaning that the content of socialization is in need of change.

Parents should be informed of the existence and the consequences of rigid sex-typing. New child rearing 
tactics that emphasize non-sex-typed behaviors and encourages cross-sex-typed play should be advocated, while the importance of gender-specific colors, toys, clothing, and games could be de-emphasized.

Socialization in the schools should change similarly.

In addition to change in the content of primary socialization, changes in societal gender arrangements are also warranted. Stockard and Johnson (1992) suggest that changes will be more effective at the macro level, where the structure of social institutions reinforces gender inequalities. I argue that not only does social functioning maintain the gender dichotomy, but also that gender stereotyping and socialization affect social functioning. Stockard and Johnson (1992) argue that institutions, as opposed to individual attitudes, are the easiest area in which to intervene and legislate societal change. Of course, legislating change does not guarantee that it will be accepted. Women's higher participation in the labor force and increased levels of education may also contribute to awareness and change of sex-role stereotypes at this level.

Overall, the findings from this research show that infants are still stereotyped by their parents on the basis of sex. Fathers were found to make the most extreme stereotypic descriptions, and both mothers and 
fathers engaged in more rigid sex-role stereotyping of sons than daughters. Further research should seek to understand gender relations at the macro as well as the micro level in American society and in particular the interplay between them.

Although the traditional gender theories all posit that gender is learned, they have failed to address the ranking of differences between the genders. Masculinity, valued more highly, represents success and strength, while femininity is devalued and perceived as weakness and dependency. Acceptance of these sex-role stereotypes will have the consequence of locking men into exclusively male activities and pushing women toward roles considered feminine. 


\section{REFERENCES}

Andersen, M. L. 1993. Thinking About Women:

Sociological Perspectives on Sex and Gender.

New York: MacMillan.

Bandura, A. 1963. Social Learning and Personality

Development. New York: Holt, Rinehart, and

Winston.

Basow, S. A. 1986. Gender Stereotypes: Traditions and Alternatives. Pacific Grove, CA: Brooks/Cole.

Bem, S. L. 1974. "The Measurement of Psychological Androgyny." Journal of Consulting and Clinical Psychology 42: 155-162.

1984. "Androgyny and Gender Schema Theory: A Conceptual and Empirical Integration." Psychology and Gender. Lincoln, NE: University of Nebraska Press.

Binion, V. 1990. "Psychological Androgyny: A Black Female Perspective." Sex Roles 22: 487-507.

Block, J., A. Vonderlipp, and J. H. Block. 1973. "Sex Role and Socialization Patterns: Some Personality Concommitments and Environmental Antecedents." Journal of Consulting and Clinical Psychology 41: $321-41$.

Block, J. H. 1973. "Conceptions of Sex Roles: Some Cross Cultural and Longitudinal Perspectives." American Psychologist 28: 512-526.

\section{Sex Roles Identity and Ego}

Development. San Francisco: Jossey.

Broverman, I. K., D. M. Broverman, F. Clarkson, and S. R. Vogel. 1968. "Sex-Role Stereotypes and Clinical Judgments of Mental Health." Journal of Consulting and Clinical Psychology 34: 1-7. 
Brown, J. D. and K. Campbell. 1986. "Race \& Gender in Music Videos: The Same Beat But a Different Drummer." Journal of Communication 36: 94-106.

Bussey, K. and A. Bandura. 1984. "Influence of Gender Constancy and Social Power on Sex-Linked Modeling." Journal of Personality and Social Psychology 47: 1292-1302.

Chodorow, N. 1978, The Reproduction of Mothering: Psychoanalysis and the Sociology of Gender. Berkeley, CA: University of California Press.

Coker, D. R. 1984. "The Relationship Among Concepts and Cognitive Maturity in Preschool Children." Sex Roles 10: 19-31.

Condry, S. M., J. C. Condry, Jr., and L. W. Pogatshnik. 1983. "Sex Differences: A Study of the Ear of the Beholder." Sex Roles 9: 697-704.

Crane, M. and H. Markus. 1982. "Gender Identity: The Benefits of a Self Schema Approach." Journal of Personality and Social Psychology 43: 1195-1197.

Culp, R. E., A. S. Cook, and P. C. Houstey. 1983. "A Comparison of Observed and Reported Adult-Infant Interactions: Effects of Perceived Sex." Sex Roles 9: 475-479.

Delboca, F. K. and R. D. Ashmore. 1980. "Sex Stereotypes Through the Life Cycle." In L. Wheeler, ed., Review of Personal and Social Psychology 1: 163-192 Beverly Hills, CA: Sage.

Doyle, J.A. 1983. The Male Experience. Dubuque, IA: William and Brown.

Eisenhart, R. W. 1975. "You Can't Hack it Little Girl: A Discussion of the Covert Psychological Agenda of Modern Combat Training." Journal of Social Issues 31: $13-23$.

Epperson, S. E. 1988. "Studies Link Subtle Sex Bias in Schools with Women's Behavior in the Workplace." Wall Street Journal, September 16, p. 27. 
Fagot, B. I. 1974. "Sex Differences in Toddler's Behavior and Parental Reaction." Developmental Psychology 10: 554-558.

Felson, R. B., and M. Reed. 1986. "The Effect of Parents on the Self-Appraisals of Children." Social Psychology Quarterly 49: 302-308.

Fling, S. and M. Manosevitz. 1972. "Sex Typing in Nursery School Children's Play Interest." Developmental Psychology 7: 46-52.

Foley, D. E. 1990. "The Great American Football Ritual: Reproducing Race, Class, and Gender Inequality." Sociology of Sport Journal 7: 111135 .

Freud, S. 1964. Standard Edition of the Complete Psychological Works of Sigmund Freud. London: Hogarth (original work published 1925).

Frieze, I. H., Parsons, P. Johnson, D. N. Ruble, and G. Zellman, eds. 1978. Women and Sex Roles. New York: Norton.

Ganong, L., and M. Coreman. 1987. "Effect of Children on Parental Sex-Role Orientation." Journal of Family Issues 8: 278-290.

Gilham, S. A. 1989. "The Marines Build Men: Resocialization in Recruit Training." In The Sociological outlook, Luhman, ed., second edition: 232-344, San Diego, CA: Collegiate Press.

Hall, R. M. with B. R. Sandler. 1982. The Classroom Climate: A Chilly One for Women?" Washington D.C.: Association of American Colleges, Project on the Status and Education of Women.

Haste, H. 1994. The Sexual Metaphor. CA: Harvard University Press.

Henslin, J. M. 1993. Sociology: A Down to Earth Approach. Needham, MA: Allyn and Bacon.

Hoffman, D. M. and I. A. Fidell. 1979. "Characteristics of Androgynous, Undifferentiated, Masculine, and Feminine Middle-Class Women." Sex Roles 5: 765-781. 
Hoffman, L. W. 1977. "Changes in Family Roles, Socialization and Sex Differences." American Psychologist 32: 644-657.

1979. "Maternal Employment: 1979." American Psychologist 34: 859-865.

Katz, P. A. 1979. "The Development of a Female Identity." Sex Roles 5: 155-78.

Kohlberg, L. 1969. Stage and Sequence: The Cognitive Developmental Approach to Socialization. Chicago: Rand McNally.

1966. "A Cognitive Developmental Analysis of Children's Sex Role Concepts and Attitudes." In E. E. MacCoby. ed., The Development of Sex Differences: 82-173, stanford, CA: Stanford University Press.

Kohlberg, L. and D. Z. Ullian. 1974. Stages in the Development of Psychosexual Concepts and Attitudes. In R. C. Freidman, R. M. Richart, and R. L. Vande Wiele, eds., Sex Differences in Behavior: 209222, New York: Wiley.

Kutner, N. and R. Levinson. 1978. "Toy Salesperson." Sex Roles 4: $1-7$.

Lansky, L. 1963. "Sex-Role Preference of Kindergarten Boys and Girls: Some Contradictory Results." Psychological Reports 13: 415-421.

Lever, J. 1978. "Sex Differences in the Complexity of Childrens Play and Games." American Sociological Review 43: 471-83.

Lips, H. 1991. Women, Men, and Power. Mountain View, CA: Mayfield.

1993. Sex and Gender, An Introduction. Mountain View, CA: Mayfield.

McArthur, L. Z., and S. V. Eisen. 1976. "Achievements of Male and Female Storybook Characters as Determinants of Achieving Behavior by Boys and Girls." Journal of Personality and Social Psychology 33: 467-473. 
McBrown, W. H. 1981. "Parental Relationships, Socioeconomic Status, and Sex Role Expectations." Sex Roles 7: 1027-1033.

McGuire, J. 1988. "Gender Stereotypes As Parents With Two-Year-Olds and Beliefs About Gender Differences in Behavior." Sex Roles 19: 233-40.

MacCoby, E. E. 1990. "Gender and Relationships." American Psychologist 45: 513-20.

MacCoby, E. E. and C. N. Jacklin. 1974. The Psychology of Sex Differences. Stanford: Stanford University Press.

Martin, C. L. 1989. "Children's Use of Gender Related Information in Making Social Judgments." Developmental Psychology 25: 80-88.

McArthur, L. Z., and S. V. Eisen. 1976. "Achievements of Male and Female Storybook Characters as Determinants of Achieving Behavior by Boys and Girls." Journal of Personality and Social Psychology 33: 467-473.

McBrown, W. H. 1981. "Parental Relationships, Socioeconomic Status, and Sex Role Expectations." Sex Roles 7: 1027-1033.

McGuire, J. 1988. "Gender Stereotypes As Parents With Two-Year-Olds and Beliefs About Gender Differences in Behavior." Sex Roles 19: 233-40.

Mills, C. J. and D. J. Tyrrell. 1983. "Sex-Stereotypic Encoding and Release from Proactive Interference." Journal of Personality and Social Psychology 45: 772-81.

Nielsen, J. M. 1990. Sex and Gender in Society: Perspectives on stratification. Illinois: Waveland Press.

O'Brien, M. and A. C. Huston. 1985. "Development of Sextyped Play Behavior in Toddlers." Developmental Psychology 21: 866-71.

Paludi, M. A. and D. F. Gullo. 1986. "The Effect of Sex Labels on Adults' Knowledge of Infant Development." Sex Roles 16: 19-30. 
Perry, P. G. and K. Bussey. 1979. "The Social Learning Theory of Sex Differences: Imitation is Alive and Well." Journal of Personality and Social Psychology 37: 1699-1712.

Power, T. 1981. "Sextyping in Infancy: The Role of the Father." Infant Mental Health Journal 2: 226240 .

Reis, P. and A. Stone. 1992. The American Women: 1992-93 Status Report; Women and Politics. New York: W. W. Norton and Company.

Rheingold, H. L. and K. V. Cook. 1975. "The Contents of Boys' and Girls' Rooms as an Index of Parents Behavior." Child Development 46: 459-63.

Richardson, L. W. 1981. The Dynamics of Sex and Gender. Boston: Houghton-Mifflin.

Roopnarine, J. 1986. "Mothers' and Fathers' Behaviors Toward the Toy Play of Their Infant Sons and Daughters." Sex Roles 14: 59-68.

Rubin, J. Z., F. J. Provenzano, and Z. Luria. 1974. "The Eye of the Beholder: Parents' Views on Sex of Newborns." American Journal of Orthopsychiatry 44: 512-519.

Sadker, M. and D. Sadker. 1985. "Sexism in the Schoolroom of the '80s." Psychology Today, March: 54-57.

1986. "Sexism in the Classroom: From Grade School to Graduate School." Phi Delta Kappan, March: 512-515.

Sapiro, V. 1994. Women in American Society. Mountain View, California: Mayfield.

Schlesinger Jr., A. M. The World Almanac 1994. Mahwah, New Jersey: Funk \& Wagnalls: 24.

Seavey, C. A., D. A. Katz, and S. R. Zalk. 1975. "Baby $X$ : The Effect of Gender Labels on Adult Responses to Infants." Sex Roles 1: 103-109. 
Spence, J. T. 1984. "Gender Identity and Its Implications for the Concepts of Masculinity and Femininity." Psychology and Gender. Lincoln, Nebraska: University of Nebraska Press.

Spence, J. T. and P. L. Helmreich. 1978. Masculinity and Femininity. Austin, Texas: University of Texas Press.

Stockard, J. and M. Johnson. 1992. Sex and Gender in Society. Englewood Cliffs, New Jersey: Prentice Hall.

Sweeny, J. and M. Bradbard. 1987. "Mothers' and Fathers' Changing Perceptions of Their Male and Female Infants Over the Course of Pregnancy." Journal of Genetic Psychology 149: 393-404.

Thompson, S. K. 1975. "Gender Labels and Early Sex Role Development." Child Development 46: 339-347.

Upman-Blumen, J. 1984. Gender Roles and Power. Englewood Cliffs, New Jersey: Prentice Hall.

Weitz, S. 1977. Sex Roles: Biological, Psychological, and Social Foundations. New York: Oxford University Press.

West, C. and D. Zimmerman. 1981. "Doing Gender." Gender and Society 1: 125-151.

White, L. and D. Brinkerhoff. 1981. "The Sexual Division of Labor: Evidence from Childhood." Social Forces 60: 170-181.

Will, J. A., P. A. Self, and N. Datan. 1976. "Maternal Behavior and Perceived Sex of Infant." American Journal of Orthopsychiatry 46: 135-39.

Williamson, N. E. 1976. Sons and Daughters: A Cross Cultural survey of Parental Preferences. Beverly Hills, CA: Sage. 
APPENDIX A

CONSENT FORM 


\section{APPENDIX A}

\section{CONSENT FORM}

I understand and give permission to be included in a study on parent-child interaction. The purpose of this study is to understand relationships between parents and their newborn infants. I specifically give permission to be interviewed, in a 10-15 minute interview, in the hospital by a trained interviewer. Secondly, I permit access by the researchers to hospital medical records only as they pertain to the birth certificate information. I further understand that this information will be kept confidential to protect me and my child's personal privacy and identity.

I may not receive any direct benefit from participation in this study, but my participation may help to increase knowledge which may benefit others in the future.

I understand that I am free to withdraw from this study at any time without jeopardizing the care that I and my child receive at the hospital.

The researcher has offered to answer any questions I have about the study and what I am expected to do.

Patient Signature:

Date:

If you have any questions about this study, please contact the Chair of the Human Subjects Research Review Committee, Office of Research \& Sponsored Projects, 105 Neuberger Hall, Portland State University, (503) 725-3417. 


\section{APPENDIX B}

INSTRUCTIONS FOR SEMANTIC DIFFERENTIAL 


\section{APPENDIX B \\ INSTRUCTIONS FOR SEMANTIC DIFFERENTIAL}

On the following page, there are 18 pairs of opposite words. You are asked to rate your baby in relation to these words, placing an "X" or a checkmark in the space that best describes your baby. The more a word describes your baby, the closer your " $X$ " should be to that word.

Example: Imagine you were asked to rate Trees;

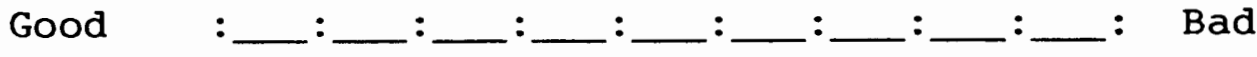

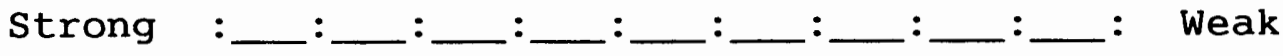

If you cannot decide or your feelings are mixed, place your " $X$ " in the center space. Remember, the more you think a word is a good description of your baby, the closer you should place your " $X$ " to that word. If there are no questions, please begin. Remember, you are rating your baby. Don't spend too much time thinking about your answers. First impressions are usually the best. 
APPENDIX C

OBJECTIVE DATA SHEET 


\section{APPENDIX C \\ HOSPITAL OBJECTIVE DATA WORKSHEET}

This information will be taken from Birth Certificate Worksheet:

Baby:

APGAR SCORES

BIRTH WEIGHT

BIRTH ORDER

IDENTIFIED RACE

Parents:

Mother Father

LAST YEAR OF EDUCATION COMPLETED

RACE

AGE 
APPENDIX D

BIRTH CERTIFICATE WORKSHEET 
M.R. NUMBER:

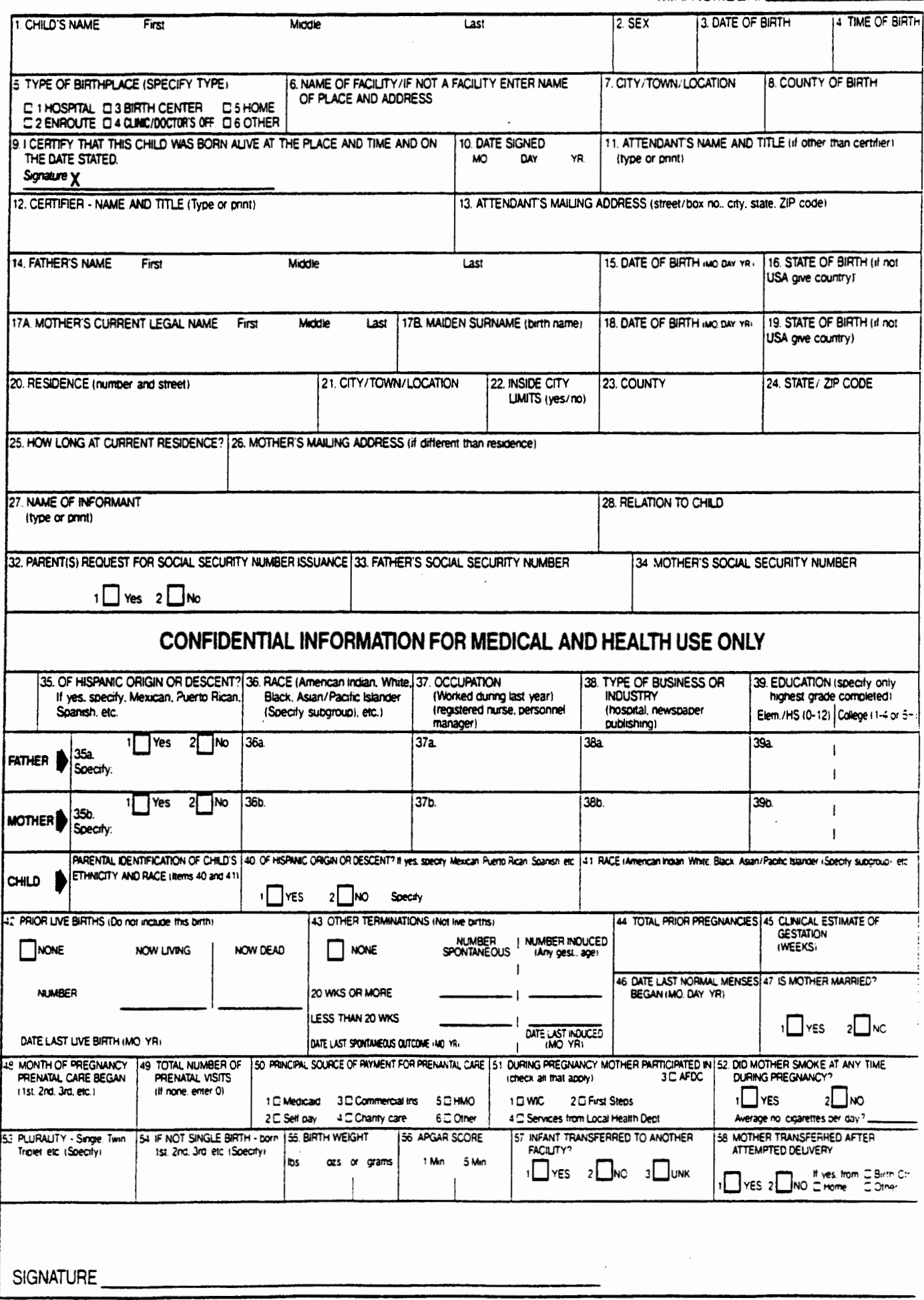


APPENDIX E

RUBIN'S SEMANTIC DIFFERENTIAL FINDINGS 


\section{APPENDIX E}

MEAN RATINGS ON THE 18 ADJECTIVE SCALES,

AS A FUNCTION OF SEX OF PARENT (MOTHER VS. FATHER)

AND SEX OF INFANT (SON vS. DAUGHTER)a

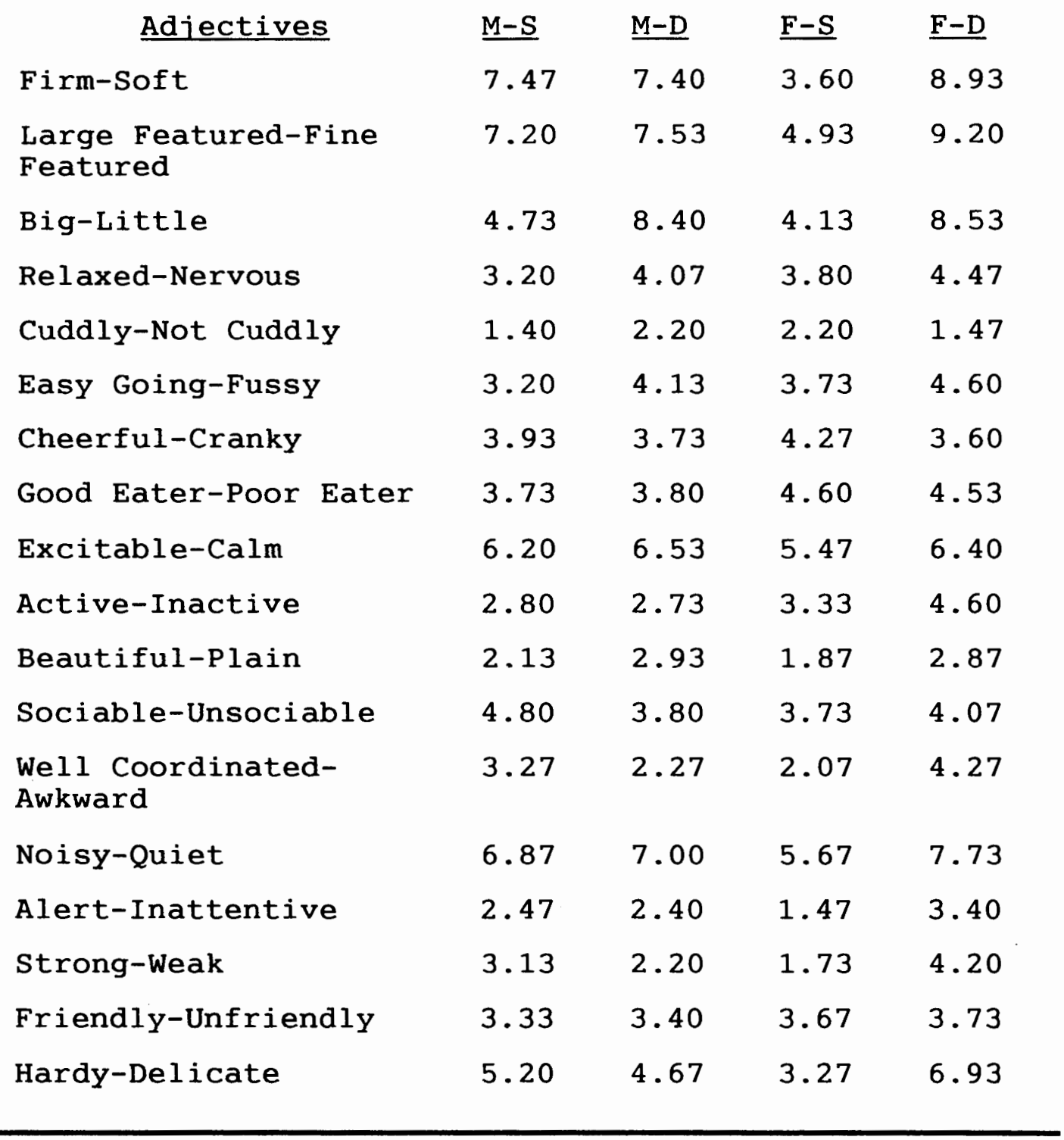

a The larger the mean, the greater the rated presence of the attribute denoted by the second (right-hand) adjective in each pair. 